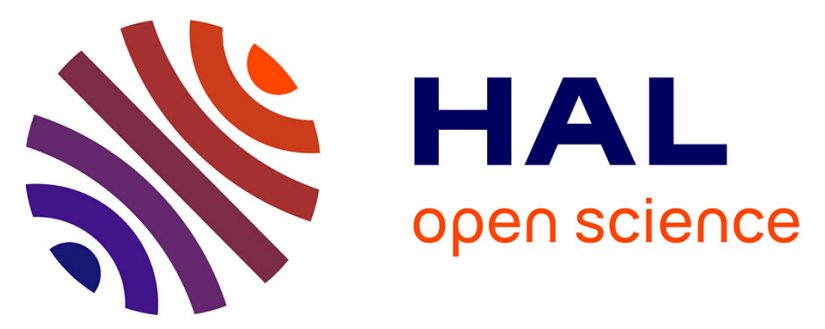

\title{
Combined processing and mutual interpretation of radiometry and fluorometry from autonomous profiling Bio-Argo floats: 2. Colored dissolved organic matter absorption retrieval
}

Xiaogang Xing, André Morel, Hervé Claustre, Fabrizio d'Ortenzio, Antoine

Poteau

\section{To cite this version:}

Xiaogang Xing, André Morel, Hervé Claustre, Fabrizio d'Ortenzio, Antoine Poteau. Combined processing and mutual interpretation of radiometry and fluorometry from autonomous profiling Bio-Argo floats: 2. Colored dissolved organic matter absorption retrieval. Journal of Geophysical Research. Oceans, 2012, 117 (C4), pp.n/a-n/a. 10.1029/2011JC007632 . hal-02168175

\section{HAL Id: hal-02168175 https://hal.science/hal-02168175}

Submitted on 12 Apr 2021

HAL is a multi-disciplinary open access archive for the deposit and dissemination of scientific research documents, whether they are published or not. The documents may come from teaching and research institutions in France or abroad, or from public or private research centers.
L'archive ouverte pluridisciplinaire HAL, est destinée au dépôt et à la diffusion de documents scientifiques de niveau recherche, publiés ou non, émanant des établissements d'enseignement et de recherche français ou étrangers, des laboratoires publics ou privés. 


\title{
Combined processing and mutual interpretation of radiometry and fluorometry from autonomous profiling Bio-Argo floats: 2. Colored dissolved organic matter absorption retrieval
}

\author{
Xiaogang Xing, ${ }^{1,2,3}$ André Morel, ${ }^{2,3}$ Hervé Claustre, ${ }^{2,3}$ Fabrizio D’Ortenzio, ${ }^{2,3}$ \\ and Antoine Poteau ${ }^{2,3}$
}

Received 27 September 2011; revised 26 January 2012; accepted 27 February 2012; published 12 April 2012.

[1] Eight autonomous profiling "Bio-Argo" floats were deployed offshore during about 2 years (2008-2010) in Pacific, Atlantic, and Mediterranean zones. They were equipped with miniaturized bio-optical sensors, namely a radiometer measuring within the upper layer the downward irradiance at 412, 490, and $555 \mathrm{~nm}$, and two fluorometers for detection of chlorophyll-a (Chla) and colored dissolved organic matter (CDOM; profiles from $400 \mathrm{~m}$ to surface). A first study dealt with the interpretation of the Chla fluorescence signal in terms of concentration, using for this purpose the diffuse attenuation coefficient for irradiance at $490 \mathrm{~nm}, \mathrm{~K}_{\mathrm{d}}(490)$, taken as a proxy for the Chla absorption. The present study examines the possibility of similarly using the $\mathrm{K}_{\mathrm{d}}(412)$ values combined with retrieved Chla profiles to convert the CDOM fluorometric qualitative information into a CDOM absorption coefficient $\left(\mathrm{a}_{\mathrm{y}}\right)$. The rationale is to take advantage of the fact that $\mathrm{K}_{\mathrm{d}}$ is more sensitive to CDOM presence at $412 \mathrm{~nm}$ than at $490 \mathrm{~nm}$. A validation of this method is tested through its application to field data, collected from a ship over a wide range of trophic conditions (Biogeochemistry and Optics South Pacific Experiment (BIOSOPE) cruise); these data include both in situ fluorescence profiles and CDOM absorption as measured on discrete samples. In addition, near-surface $\mathrm{a}_{\mathrm{y}}$ values retrieved from the floats agree with those derivable from ocean color imagery (Moderate Resolution Imaging Spectroradiometer (MODIS-A)). The low sensitivity of commercially available CDOM fluorometers presently raises difficulties when applying this technique to open ocean waters. It was nevertheless possible to derive from the floats records meaningful time series of CDOM vertical distribution.

Citation: Xing, X., A. Morel, H. Claustre, F. D’Ortenzio, and A. Poteau (2012), Combined processing and mutual interpretation of radiometry and fluorometry from autonomous profiling Bio-Argo floats: 2. Colored dissolved organic matter absorption retrieval, J. Geophys. Res., 117, C04022, doi:10.1029/2011JC007632.

\section{Introduction and Motivations}

[2] With a permanent deployment of about 3000 freedrifting profiling floats, the Argo project [Roemmich et al., 2009] is now in its fully operational phase; these floats allow more than 100 thousands temperature and salinity (T-S) profiles to be collected each year in the world ocean. This remarkable success is triggering the development and implementation of another parallel project that aims at determining in a similar way some biochemical and bio-optical

\footnotetext{
${ }^{1}$ College of Physical and Environmental Oceanography, Ocean University of China, Qingdao, China.

${ }^{2}$ Laboratoire d'Océanographie de Villefranche, Unité Mixte de Recherche 7093, Université Pierre et Marie Curie, Villefranche-sur-Mer, France.

${ }^{3}$ Laboratoire d'Océanographie de Villefranche, Unité Mixte de Recherche 7093, Centre National de la Recherche Scientifique, Villefranche-sur-Mer, France.
}

Copyright 2012 by the American Geophysical Union. 0148-0227/12/2011JC007632 properties within the ocean interior [Johnson et al., 2009; Claustre et al., 2010; International Ocean-Color Coordinating Group (IOCCG), 2011]. Such a goal became reachable thanks to the development during the last decade of miniaturized, low power consumption, sensors, which can be integrated on autonomous underwater vehicles or profiling platforms like the already existing floats. The Bio-Argo floats dealt with in the present study are free-drifting profilers, equipped with several optical sensors including a beam transmissometer, a backscattering sensor, a chlorophyll fluorometer, a radiometer measuring downward irradiance at three wavelengths (412, 490 , and $555 \mathrm{~nm}$ ), and a sensor measuring the fluorescence emitted by soluble organic matter. The present study principally deals with the processing of the last sensor signals, and its interpretation which also involves information provided by other sensors on the float.

\subsection{Background}

[3] Since the first investigations by Kalle [1938], it has been recognized that dissolved organic compounds transmit 
yellow light, leading Kalle to coin the name "Gelbstoff" (i.e., "yellow substance") to collectively designate the complex mixture of these substances, which preferentially absorb light at the blue end of the visible spectrum. Actually their absorption coefficient steadily rises with decreasing wavelength [Jerlov, 1968, Figure 19]. Kalle [1949, 1966] also found that apparently the same materials are able to exhibit a blue fluorescence when excited by short wave radiation. Relationships between both optical properties (absorbance and fluorescence) do not seem to be ubiquitous; in wide zones and stable mesopelagic or abyssal environments, however, linear correlations were observed [e.g., Yamashita and Tanoue, 2009]. The initial name introduced by Kalle is often replaced in modern literature by "Colored (or Chromophoric) Dissolved Organic Material," abbreviated as "CDOM." This equivalent acronym will also be used in what follows concurrently with the original term "yellow substance."

\subsection{Motivations}

[4] As a substrate to heterotrophic activity in the upper layers and deep layers as well, dissolved organic carbon (DOC) plays a "central role in the ocean carbon cycle" [Hansell, 2002], and represents the second largest bioreactive pool of carbon in the ocean. Spatial and temporal DOC distributions are not well documented, essentially because of analytical difficulties. It has been tempting to use both the CDOM optical properties (absorption and fluorescence) as potential proxies for DOC [see, e.g., Chen and Bada, 1992; Vodacek et al., 1997]. Actually, DOC/CDOM relationships may vary in time and space (depth), as does the composition of the organic mixture itself [see, e.g., Coble, 2007; Omori et al., 2011; Jørgensen et al., 2011]. In the Sargasso Sea, for instance, no quantitative link was observed [Nelson et al., 1998]. Generally, DOC and fluorescence seem positively correlated in various estuarine and coastal waters [Chen and $B a d a, 1992$, and references therein]. In contrast, negative correlations were often observed along the depth in oceanic environments [Chen and Bada, 1992; Omori et al., 2011]. Such negative correlations can result from CDOM photodegradation by sunlight in the upper layers [Kramer, 1979] without impact on the DOC pool, whereas a CDOM regeneration or replenishment occurs below the mixed layer, where DOC tends to be oxidized.

[5] Even if CDOM does not provide a reliable estimate of DOC everywhere, it remains, locally, a qualitative descriptor of this pool, of its interaction with the algal biomass or of the signature of terrestrial riverine influences. On the other hand, CDOM is definitely an essential component of the optical properties in all kinds of waters, not only coastal but also clear oceanic ones [e.g., Siegel et al., 2005; Morel et al., 2010]. As such, it is an essential parameter, not easily measured through conventional techniques (spectrophotometry), but more accessible through its fluorescence capacity.

\subsection{Specific Purposes}

[6] The present work is focused on a combined processing and interpretation of the data provided by two particular instruments embarked on the floats, namely the CDOM fluorometer and the radiometer. It examines the link that can be established between the two types of determinations, and the benefit which can be gained from such a combination. In a previous study [Xing et al., 2011], the attenuation coefficients for downward irradiance at $490 \mathrm{~nm}$, as derived from radiometer data, were used to calibrate the chlorophyll fluorescence profiles in absolute units of chlorophyll-a concentration $\left(\mathrm{mg} \mathrm{m}^{-3}\right)$, thereafter denoted [Chla]. In open ocean (case 1) waters, the attenuation coefficient at $490 \mathrm{~nm}$ is essentially governed by the phytoplanktonic and related materials (coexisting heterotrophic organisms, and various accompanying debris). The influence of the yellow substance on the attenuation coefficient is considerably more pronounced at $412 \mathrm{~nm}$ than at $490 \mathrm{~nm}$, because of the exponential increase in absorption toward shorter wavelengths; therefore the former wavelength is better adapted to get information on the CDOM content, while the latter was selected for [Chla] retrieval [Xing et al., 2011]. Information which is expected from a combined treatment of fluorescence and irradiance data is a quantification of the yellow substance content in terms of absorption coefficient.

\section{Materials and Methods}

\subsection{Instruments and Data}

[7] The "Bio-Argo" floats used here are the so-called PROVBIO; they are based on PROVOR CTS3 free-drifting profilers (NKE instrumentation, France), equipped with independent bio-optical sensors, namely a OC4 radiometer (Satlantic, Halifax, Canada) and a BBFL2 sensor (WET Labs, Inc., Philomath, OR, USA). The OC4 radiometer measures the downward planar irradiance, $E_{\mathrm{d}}$, at three wavelengths, $\lambda=412,490$, and $550 \mathrm{~nm}$; the $\mathrm{E}_{\mathrm{d}}(\lambda)$ values are expressed as $\mu \mathrm{W} \mathrm{cm}{ }^{-2} \mathrm{~nm}^{-1}$ according to the calibration provided by the manufacturer (note that the fourth spectral channel of the standard OC4 was used to retrieve the transmissometer signal). The BBFL2 sensor is an optical sensor of the ECO triplet class. In the configuration used in the present study, one channel of the BBFL2 is dedicated to backscattering measurement at $532 \mathrm{~nm}$, one to Chla fluorescence measurement [see Xing et al., 2011], and one to $\mathrm{CDOM}$ fluorescence measurement (excitation at $370 \mathrm{~nm}$, emission at $460 \mathrm{~nm}$ ). The raw signal output of the CDOM fluorescence sensor (digital counts) is first corrected by subtracting the nominal dark counts; then, the residual signal is multiplied by a linear scale factor to obtain an equivalent concentration (as ppb) of the fluorescing solution that is used for the calibration (quinine sulfate diluted in weak sulfuric acid). Dark counts and scale factors are specific of each instrument and available on the characterization sheets delivered by the manufacturer. For the CDOM fluorescence sensor, the CDOM dark counts (30 to 50 counts) are not dependent on temperature over the $1^{\circ}-25^{\circ} \mathrm{C}$ range, as verified by Proctor and Roesler [2010].

[8] The nominal mission of a float consists of acquiring a T-S profile during the ascent (vertical speed $\sim 0.1-0.2 \mathrm{~m} \mathrm{~s}^{-1}$ ) from the parking depth (about $1000 \mathrm{~m}$ ) up to the surface. The bio-optical sensors were normally programmed to start their data acquisition only from a depth of about $400 \mathrm{~m}$; the fluorescence signals, however, were also systematically measured at $1000 \mathrm{~m}$, just before the ascent, to control the stability of the sensors, in particular with respect to a possible fouling. Actually, the signals at $1000 \mathrm{~m}$ were remarkably stable in time (the variability was less than $4 \%$; see Table 3). The absence of fouling was also attested by the 
Table 1. Relevant Information Concerning the Eight PROVBIO Floats Involved

\begin{tabular}{lccc}
\hline \multicolumn{1}{c}{ Float $^{\mathrm{a}}$} & Area & Start Date & End Date \\
\hline MED_NW_B02 & Mediterranean Sea & 1 May 2008 & 14 Mar 2010 \\
MED_LV_B06 & Mediterranean Sea & 27 Jun 2008 & 8 Nov 2009 \\
NAT_IB_B03 & North Atlantic & 30 Jun 2008 & 12 May 2010 \\
NAT_IS_B01 & North Atlantic & 1 Jul 2008 & 17 May 2009 \\
PAC_NO_B05 & North Pacific & 15 Aug 2008 & 29 Oct 2009 \\
PAC_NO_B08 & North Pacific & 15 Aug 2008 & 26 Feb 2011 \\
PAC_SO_B04 & South Pacific & 3 Dec 2008 & 6 Mar 2010 \\
PAC_SO_B07 & South Pacific & 3 Dec 2008 & 50 \\
Total & & & 50 \\
\hline
\end{tabular}

${ }^{\mathrm{a}}$ The trajectories of the floats during their entire life can be seen at http://www.obs-vlfr.fr/OAO.

clean state of the sensors, which were retrieved after 23 months of operation in western Mediterranean Sea.

[9] When a float has emerged, the two-way communication (via iridium satellite communication) allows the transmission of its data and a possible reprogramming of its future cast before the float returns downward to its parking depth. The frequency of the casts was normally one per 10 days, but more frequent acquisitions were sometimes programmed. Ascents were generally scheduled to perform irradiance measurements around the local noon, when favorable illumination conditions are expected.

[10] Eight identical PROVBIO floats were operated. They were deployed during the 2008-2010 period in the Mediterranean Sea, North Atlantic, and North Pacific, near the Hawaiian Islands, and in South Pacific, near Rapa Nui (Easter Island). Table 1 provides the identifying acronyms for each float together with periods (lifetime) and locations.

\subsection{Theoretical Framework}

[11] Some basic definitions and already published empirical relationships are reported below, before they are utilized to develop a processing method for the CDOM fluorescence profiles. These relationships deal with $\mathrm{K}_{\mathrm{d}}$ (units $\mathrm{m}^{-1}$ ), the diffuse attenuation coefficient for downward irradiance, with $a$ and $b_{b}$, the absorption and backscattering coefficient, respectively (units $\mathrm{m}^{-1}$ ), and finally with the relationship that can be established between them. The spectral attenuation coefficient, $\mathrm{K}_{\mathrm{d}}(\lambda)$, is derived from radiometric measurements at the wavelength $\lambda$, whereas the spectral absorption coefficient, $a(\lambda)$, which is partly determined by the CDOM concentration, is not measured by the floats. The goal of the present study is thus to examine the possibility of extracting from the magnitude and variations of $\mathrm{K}_{\mathrm{d}}$ an estimate of that part of absorption which is attributable to yellow substance.

[12] The diffuse attenuation coefficient for downward irradiance, $\mathrm{K}_{\mathrm{d}}$, is defined as the vertical gradient of the naperian logarithm of the downward planar irradiance, $\mathrm{E}_{\mathrm{d}}$, according to (wavelength omitted)

$$
\mathrm{K}_{\mathrm{d}}=-\mathrm{d}\left[\operatorname{Ln} \mathrm{E}_{\mathrm{d}}(z)\right] / \mathrm{d} z=-\left(1 / \mathrm{E}_{\mathrm{d}}\right) \mathrm{d} \mathrm{E}_{\mathrm{d}} / \mathrm{d} z
$$

In practice, $\mathrm{K}_{\mathrm{d}}$ is computed over an appropriate finite depth interval $\Delta \mathrm{z}$ (about $1 \mathrm{~m}$, in the present experiments), according to

$$
\mathrm{K}_{\mathrm{d}}=-\left[\operatorname{LnE}_{\mathrm{d}}(z+\Delta z)-\operatorname{LnE}_{\mathrm{d}}(z)\right] / \Delta z
$$

[13] The link between $\mathrm{K}_{\mathrm{d}}$ and the absorption coefficient, a, rests on an expression (equation (3)) established by Gordon
[1989]. This author showed that the quantity $\mathrm{K}_{\mathrm{d}} \mu_{\mathrm{d}}$ can be regarded as a quasi inherent optical property; $\mu_{\mathrm{d}}$ is the average cosine for downward irradiance (i.e., the ratio of downward planar irradiance to downward scalar irradiance). Consequently, $\mathrm{K}_{\mathrm{d}} \mu_{\mathrm{d}}$ can be algebraically expressed as a function of true inherent properties, namely the absorption and backscattering coefficients, according to

$$
\mathrm{K}_{\mathrm{d}}=1.0395\left(\mu_{\mathrm{d}}\right)^{-1}\left(\mathrm{a}+\mathrm{b}_{\mathrm{b}}\right)
$$

Another consequence of the near-validity of the LambertBeer law for the quantity $\mathrm{K}_{\mathrm{d}} \mu_{\mathrm{d}}$, lies in that the additivity principle holds true with respect to the partial contributions of the various individual constituents. This property will be exploited later on. The absorption coefficient of a water body can be split into three partial absorption coefficients

$$
\mathrm{a}(\lambda)=\mathrm{a}_{\mathrm{w}}(\lambda)+\mathrm{a}_{\mathrm{p}}(\lambda)+\mathrm{a}_{\mathrm{y}}(\lambda)
$$

where three distinct absorbing components are identified, namely, the pure seawater component (subscript w), the whole suspended particulate material (subscript $p$ ), and the dissolved yellow substance (subscript y). In open oceanic case 1 waters, the last two terms essentially result from biological activity that has created particles (living organisms and inanimate debris), as well as dissolved organic matter (occasionally, atmospheric deposition may contribute to the particle pool).

[14] The spectral values of the particle absorption, $a_{p}(\lambda)$, have been statistically studied as a function of [Chla] in oceanic waters [Bricaud et al., 1998]; the general form of these empirical nonlinear relationships is

$$
\mathrm{a}_{\mathrm{p}}(\lambda,[\mathrm{Chl} a])=\mathrm{A}_{\mathrm{p}}(\lambda)[\mathrm{Chl} a]^{\mathrm{Bp}(\lambda)}
$$

and for the wavelength $412 \mathrm{~nm}$, thereafter considered

$$
\mathrm{a}_{\mathrm{p}}(412,[\mathrm{Chl} a])=0.0473[\mathrm{Chl} a]^{0.686}
$$

[15] When using equation (3) we will assume that on average $\mu_{\mathrm{d}}$ amounts to $\sim 0.8$. Actually $\mu_{\mathrm{d}}$ may vary (by about $\pm 10 \%$ ) around this mean value, as it depends on the sun position and on the water optical properties (thus on [Chla]) [see Morel and Gentili, 2004, Figures 14 and 15]; lookup table available over Internet (oceane.obs-vlfr.fr,cd $\mathrm{pub}$ /morel,files f,fprime,mud). With float measurements normally performed near noon, the Sun-zenith distance was never very large, so that the $\mu_{\mathrm{d}}$ variations around 0.8 are 
reduced accordingly. Under this approximation, equation (3) will be simply written

$$
\mathrm{K}_{\mathrm{d}}=1.3\left(\mathrm{a}+\mathrm{b}_{\mathrm{b}}\right)
$$

By using the additivity principle, the absorption and backscattering coefficients can be expanded, and their partial components introduced; therefore $\mathrm{K}_{\mathrm{d}}$ becomes

$$
\begin{aligned}
\mathrm{K}_{\mathrm{d}}(\lambda)= & 1.3\left[\mathrm{a}_{\mathrm{w}}(\lambda)+\mathrm{b}_{\mathrm{bsw}}(\lambda)\right] \\
& +1.3\left[\mathrm{a}_{\mathrm{p}}(\lambda, \text { Chla } a)+\mathrm{b}_{\mathrm{bp}}(\lambda, \text { Chl } a)+\mathrm{a}_{\mathrm{y}}(\lambda)\right]
\end{aligned}
$$

The first bracket (multiplied by 1.3) corresponds to that part of attenuation which is due to the (pure) seawater itself. Adopting the Pope and Fry's [1997] value, $0.0045 \mathrm{~m}^{-1}$ for $\mathrm{a}_{\mathrm{w}}(412)$, and Morel's [1974] value for $\mathrm{b}_{\mathrm{bsw}}(412)=$ $1 / 2 b_{\mathrm{sw}}(412)=0.0034 \mathrm{~m}^{-1}$, this partial attenuation amounts to $\sim 0.01 \mathrm{~m}^{-1}$. The second term corresponds to the other component of attenuation, due to the whole material of biological origin, present in oceanic case 1 waters (i.e., in waters outside of any significant terrestrial influence). This biological material comprises the particulate matter (phytoplankton plus accompanying detrital particles and heterotrophic organisms), and the dissolved organic substances. The backscattering scattering coefficient, $b_{b p}$ is small compared to $\mathrm{a}_{\mathrm{p}}$ (about $10 \%$ at $412 \mathrm{~nm}$; see Appendix A). This effect can be simply accounted for by multiplying the $\mathrm{a}_{\mathrm{p}}(412)$ term by 1.1 , so that

$$
\mathrm{K}_{\mathrm{d}}(412)=0.01+1.3\left[1.1 \mathrm{a}_{\mathrm{p}}(412, \mathrm{Chl} a)+\mathrm{a}_{\mathrm{y}}(412)\right]
$$

and by reinserting the $a_{p}(412)$ value provided by equation ( $\left.5 b\right)$, equation (8) can be finally written as

$$
\mathrm{K}_{\mathrm{d}}(412)=0.01+0.0676[\mathrm{Chl} a]^{0.686}+1.3 \mathrm{a}_{\mathrm{y}}(412)
$$

The quantity $\mathrm{a}_{\mathrm{y}}(412)$ which is sought for can thus be retrieved from the local $\mathrm{K}_{\mathrm{d}}(412)$ and [Chla] values. It is worth noting that the two terms for particulate and dissolved materials are, on average, almost equal (see equation (15), where the $\mathrm{a}_{\mathrm{y}}$ term is expressed as a function of [Chla]). The validity and expected accuracy of this equation will be examined in Discussion and Conclusions.

\subsection{Derivation of $a_{y}(412)$ Profiles From $E_{d}(412)$ Profiles}

[16] Practically, this derivation follows a computational scheme akin to the one developed in a previous paper for the chlorophyll retrieval [Xing et al., 2011]. From its value at the surface (at null depth, denoted $0^{-}$), the downward irradiance, $\mathrm{E}_{\mathrm{d}}(\lambda, \mathrm{Z})$, decreases with increasing depth; at a certain depth, $Z$, it becomes

$$
\ln \mathrm{E}_{\mathrm{d}}(\lambda, Z)=\ln \mathrm{E}_{\mathrm{d}}\left(\lambda, 0^{-}\right)-\int_{0}^{Z} \mathrm{~K}_{\mathrm{d}}(\lambda, z) \mathrm{d} z
$$

The attenuation coefficient, $\mathrm{K}_{\mathrm{d}}(\lambda, \mathrm{z})$ (equation (1)) is allowed to vary with depth. The integral represents a dimensionless "optical depth" corresponding to the geometric $0-\mathrm{Z}$ depth interval. The irradiance profiles as measured by the floats actually are formed by a series of discrete data, $E_{d}(\lambda, Z)$, with a vertical resolution $\Delta \mathrm{z}$ of about $1 \mathrm{~m}$. The above relationship is thus replaced by a summation over the $N$ discrete layers within the 0 and $\mathrm{Z}$ interval, such as

$$
\ln \mathrm{E}_{\mathrm{d}}(\lambda, \mathrm{Z})=\ln \mathrm{E}_{\mathrm{d}}(\lambda, 0-)-\sum_{1}^{N} \mathrm{~K}_{\mathrm{d}}(\lambda, z) \Delta z
$$

By using equations (9), and the local $K_{d}(412)$, equation (11) can thus be expressed as

$$
\begin{aligned}
\ln \mathrm{E}_{\mathrm{d}}(412, \mathrm{Z})= & \ln \mathrm{E}_{\mathrm{d}}(412,0-)-\sum_{1}^{N} \\
& \cdot\left\{0.01+0.0676[\text { Chl } a](z)^{0.686}\right\} \Delta z \\
& -1.3 \sum_{1}^{N} \mathrm{a}_{\mathrm{y}}(412, z) \Delta z
\end{aligned}
$$

This equation can be written in a simplified manner

$$
\mathrm{B}_{\mathrm{n}}(412, \mathrm{Z})=\mathrm{B}_{0}(412,0-)-1.3 \sum_{1}^{N} \mathrm{a}_{\mathrm{y}}(412, z) \Delta z
$$

where $\mathrm{B}_{0}(412,0-)$ represents $\ln \mathrm{E}_{\mathrm{d}}(412,0-)$, and

$\mathrm{B}_{\mathrm{n}}(412, \mathrm{Z})=\ln \mathrm{E}_{\mathrm{d}}(412, \mathrm{Z})+\sum_{1}^{N}\left\{0.01+0.0676[\mathrm{Chl} a](\mathrm{z})^{0.686}\right\} \Delta z$

Between two successive depths of determinations, $Z_{n}$ and $Z_{n+1}$, equation (12b) becomes

$$
B_{n}\left(412, Z_{n+1}\right)=B_{n}\left(412, Z_{n}\right)-1.3 a_{y}(412, Z)\left(Z_{n+1}-Z_{n}\right)
$$

where $a_{y}(412, Z)$ is the mean value of $a_{y}$ between $Z_{n}$ and $\mathrm{Z}_{\mathrm{n}+1}$, that can be obtained through

$$
\mathrm{a}_{\mathrm{y}}(412, \mathrm{Z})=\left[\mathrm{B}_{\mathrm{n}}\left(412, \mathrm{Z}_{\mathrm{n}}\right)-\mathrm{B}_{\mathrm{n}}\left(412, \mathrm{Z}_{\mathrm{n}+1}\right)\right] / 1.3\left(\mathrm{Z}_{\mathrm{n}+1}-\mathrm{Z}_{\mathrm{n}}\right)
$$

[17] Practically, successive $B_{n}(Z)$ values are computed (equation (13)) from the successive $\mathrm{E}_{\mathrm{d}}(412, \mathrm{Z})$ data, and by using the $[\mathrm{Chl} a](\mathrm{z})$ values, which are simultaneously derived from the $\mathrm{E}_{\mathrm{d}}(490, \mathrm{Z})$ profiles according to the method developed in [Xing et al., 2011]. Figure 1c shows an example of such a $B_{n}(Z)$ profile. The raw $B_{n}$ values are represented as black symbols; for subsequent computations it is convenient to smooth the $\mathrm{B}_{\mathrm{n}}$ profiles by using a spline function (represented as the black curve). Then, the $\mathrm{a}_{\mathrm{y}}(412, \mathrm{Z})$ values are obtained step by step by forming the differences as specified by equation (14b); Figure 1b shows an instance of such an $\mathrm{a}_{\mathrm{y}}$ profile.

[18] The $E_{d}(412, Z)$ and $E_{d}(490, Z)$ profiles may be affected by passing clouds; except in adverse conditions (many clouds), such disturbances, including those occurring near the surface, can be corrected for according to a procedure already described in the work of Xing et al. [2011].

\subsection{Validation of the Proposed Method}

[19] A validation of the above method aiming at retrieving the yellow substance absorption from $\mathrm{K}_{\mathrm{d}}(412)$ values is possible by considering field data collected from a ship, under well controlled conditions. The BIOSOPE cruise [Claustre et al., 2008] along a $8000 \mathrm{~km}$ transect in the 

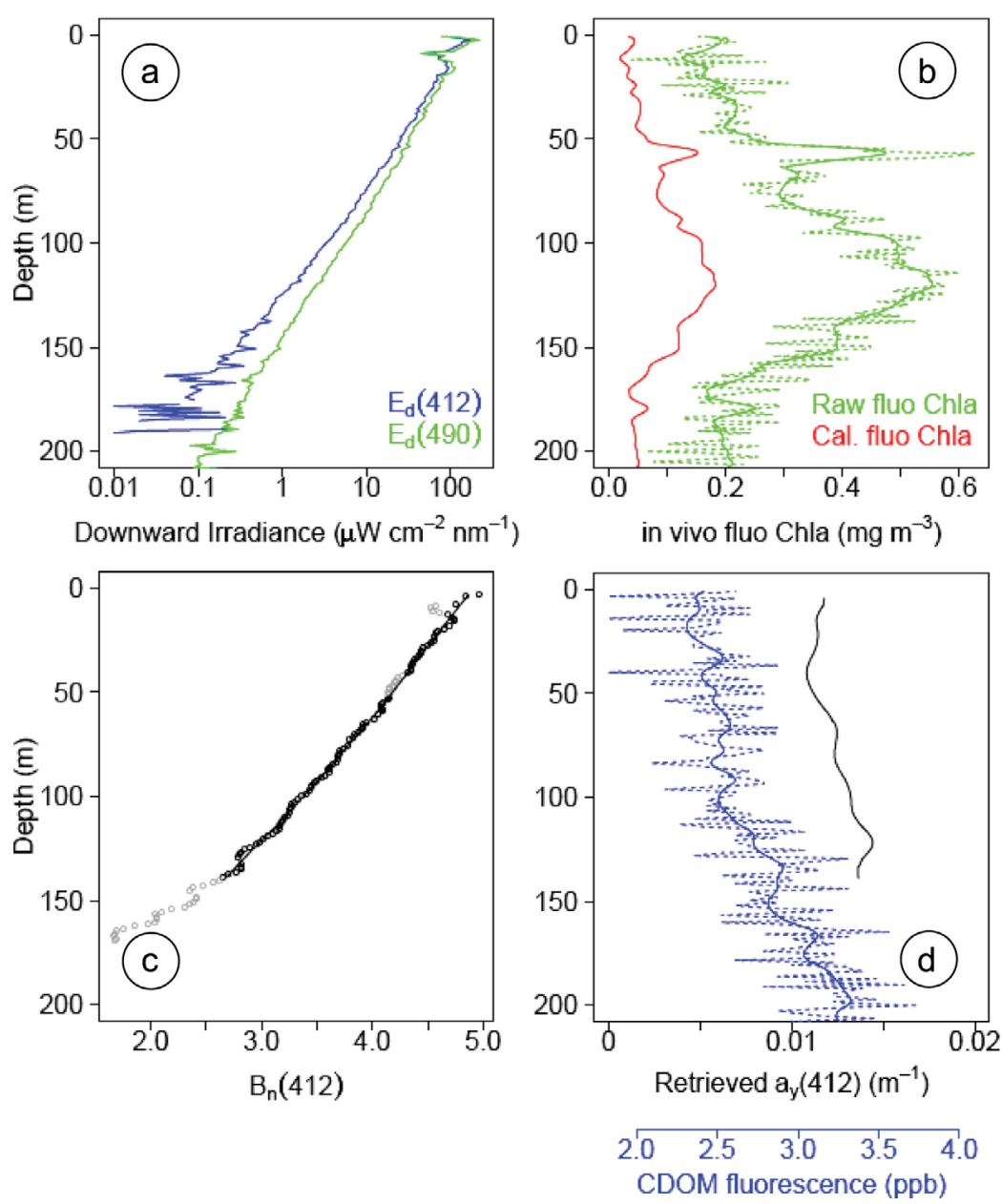

Figure 1. Examples of raw data recorded in North Pacific on 23 March 2009 (float PAC_NO B05, cycle $27,21: 44 \mathrm{GMT}, 26.013^{\circ} \mathrm{N}, 160.199^{\circ} \mathrm{W}$ ) and of processed data: (a) downward irradiances profiles at 412 and $490 \mathrm{~nm}$; (b) raw Chl-a fluorometric profile and calibrated [Chla] profile as $\mathrm{mg} \mathrm{m}^{-3}$ [Xing et al., 2011]; (c) profile of the parameter $\mathrm{B}_{\mathrm{n}}(412)$ defined in equation (14); (d) raw CDOM fluorometric data (units of quinine sulfate concentration as parts per billion) and retrieved CDOM absorption coefficient (at $412 \mathrm{~nm}$, units of $\mathrm{m}^{-1}$, black curve).

Southeast Pacific, from Marquesas Islands to Concepcion (Chile), provides the needed information. The $\mathrm{E}_{\mathrm{d}}(412)$ profiles were determined with a sensor similar to those mounted on the floats, and yellow substance absorption spectra were determined [Bricaud et al., 2010] on discrete samples by using a liquid core waveguide technique [Miller et al., 2002], as implemented in the Ultrapath system (Ultrapath, WPI Inc., Saratoga, FL, USA).

[20] The results of the full validation exercise for all (19) stations along the transect are displayed on vertical sections which show the absorption coefficient $\mathrm{a}_{\mathrm{y}}(412)$, as directly measured (Figure 2a), and as continuously retrieved (Figure 2b) from the irradiance profiles in the same stations. Despite very low absorption values in this oceanic region (particularly in its central part) [Morel et al., 2007a, 2007b, 2010], a qualitative agreement regarding the spatial distribution can be observed. The smoother aspect of the patterns in Figure $2 b$ (compared to those in Figure 2a) results from the continuous character of the $\mathrm{a}_{\mathrm{y}}$ profiles when derived from the irradiance profiles, while the direct determinations (displayed in Figure 2a) result from discrete and spaced sampling. The quantitative agreement, exemplified by the scatterplot (Figure 3), is rather fair; nevertheless it confirms that very low $\mathrm{a}_{\mathrm{y}}$ values can be detected through the present method. Indeed, most of the $\mathrm{a}_{\mathrm{y}}(412)$ data (in the hyperoligotrophic central part) are below $\sim 0.04 \mathrm{~m}^{-1}$; they only reach $\sim 0.08 \mathrm{~m}^{-1}$ in the Chilean coastal upwelling zone. As far as we know, there are no published results, similar to those in Figure 3, comprising concomitant Ultrapath determinations and radiometric profiles in open ocean environments, which would allow Figure 3 to be supplemented and the present method to be more thoroughly validated.

\subsection{Operational Relationships Between Fluorescence Signals and CDOM Absorption Coefficients}

[21] According to a common protocol, the signals provided by fluorescence sensors are scaled to a concentration of quinine sulfate, and expressed as ppb of this substance. If calibrations performed by the manufacturer with respect to this standard are obtained in rigorous and reproducible conditions, and if they are stable, a useful (albeit arbitrary) fluorescence index is available for quantifying the marine 


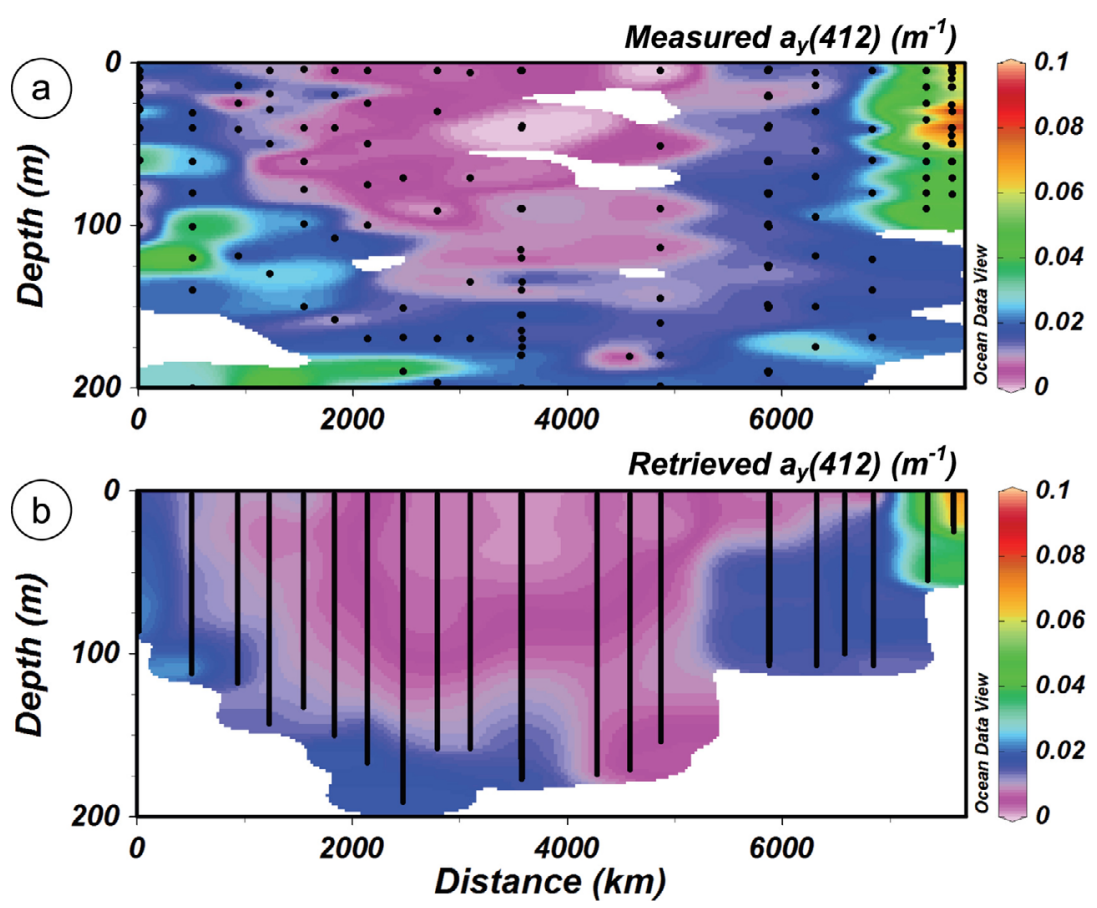

Figure 2. From west to east: BIOSOPE cruise between Marquesas Archipelago and Chilean coast. (a) Vertical section showing the measured absorption coefficient at $412 \mathrm{~nm}$ of CDOM, as measured on samples (represented by dots). (b) CDOM absorption coefficient (profiles represented by vertical bars) retrieved from irradiance measurements at 412 and [Chla] (derived from irradiance measurements at $490 \mathrm{~nm})$. The color scale is the same for Figures 2a and 3b.

fluorescing material. It could be used as well as for temporal/ spatial studies and intersensor comparisons, provided that the various sensors are coherently intercalibrated. There are, however, considerable discrepancies between sensors operating in parallel (examples in Figure 4a). Note that each pair of floats (in North and South Pacific,) was deployed on the same day and at the same location. Visualization (Figures $4 \mathrm{~b}$ and 4c) on depth/time diagrams of the fluorometric data (ppb) reveals a persistent disagreement between the two instruments deployed in the same zone. Logically, such a discrepancy must be attributed to differences in sensor calibrations used to convert output values (counts) into ppb units.

[22] Diverging calibrations are clearly evidenced by plotting for all sensors the "ppb returns" versus the corresponding $\mathrm{a}_{\mathrm{y}}(412)$ values, as retrieved from irradiance data, and available at the same depths (Figures 5a, 5b, 5c, and $5 \mathrm{~d}$ ). Instances of such differing calibrations can be seen in Figures $5 \mathrm{a}$ and $5 \mathrm{~b}$ (for the northern and southern Pacific, respectively); for each pair of floats, the ppb values form two distinct, actually two parallel, patterns, with similar slopes and mainly differing by their respective intercepts. In the Mediterranean Sea (Figure 5c), the two floats were not deployed at the same location, but their responses were apparently similar. In the North Atlantic (Figure 5d), the corresponding regression lines are almost horizontal, so that there is only a small variation in the ppb index, whatever the $\mathrm{a}_{\mathrm{y}}$ value. Apart from these sensors, the ppb and $\mathrm{a}_{\mathrm{y}}(412)$ values appear for the other sensors to be reasonably well correlated. The results of separate linear regression analyses are provided in Table 2. Even if the coefficients of determination are not very high, these empirical equations were nevertheless used as tools to convert fluorometric signals $(\mathrm{ppb})$ into absorption coefficients $\left(\mathrm{m}^{-1}\right)$.

[23] The high intercepts found in the linear regressions between ppb and $\mathrm{a}_{\mathrm{y}}$ are somewhat surprising. These intercepts (see Table 2 and Figures 5a, 5b, 5c, and 5d) are between 1.5 and $3.5 \mathrm{ppb}$ according to the instruments; they actually exceed the range of variations locally observed in oceanic environments (of the order of $1 \mathrm{ppb}$ ). According to

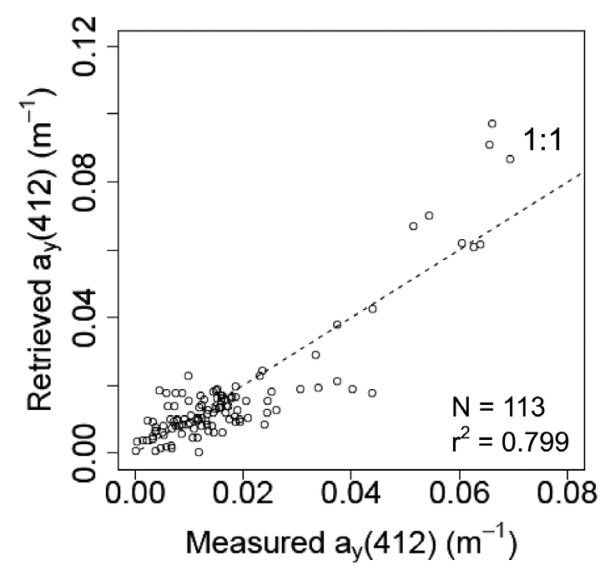

Figure 3. Scatterplot of the same data as in Figure 2; retrieved versus measured CDOM absorption coefficient. The $r^{2}$ value as indicated is for the entire set of data (113); if restricted to absorption values below $0.04 \mathrm{~m}^{-1}$ (data from the upwelling zone excluded $), r^{2}$ drops to $0.446(\mathrm{~N}=105)$. 

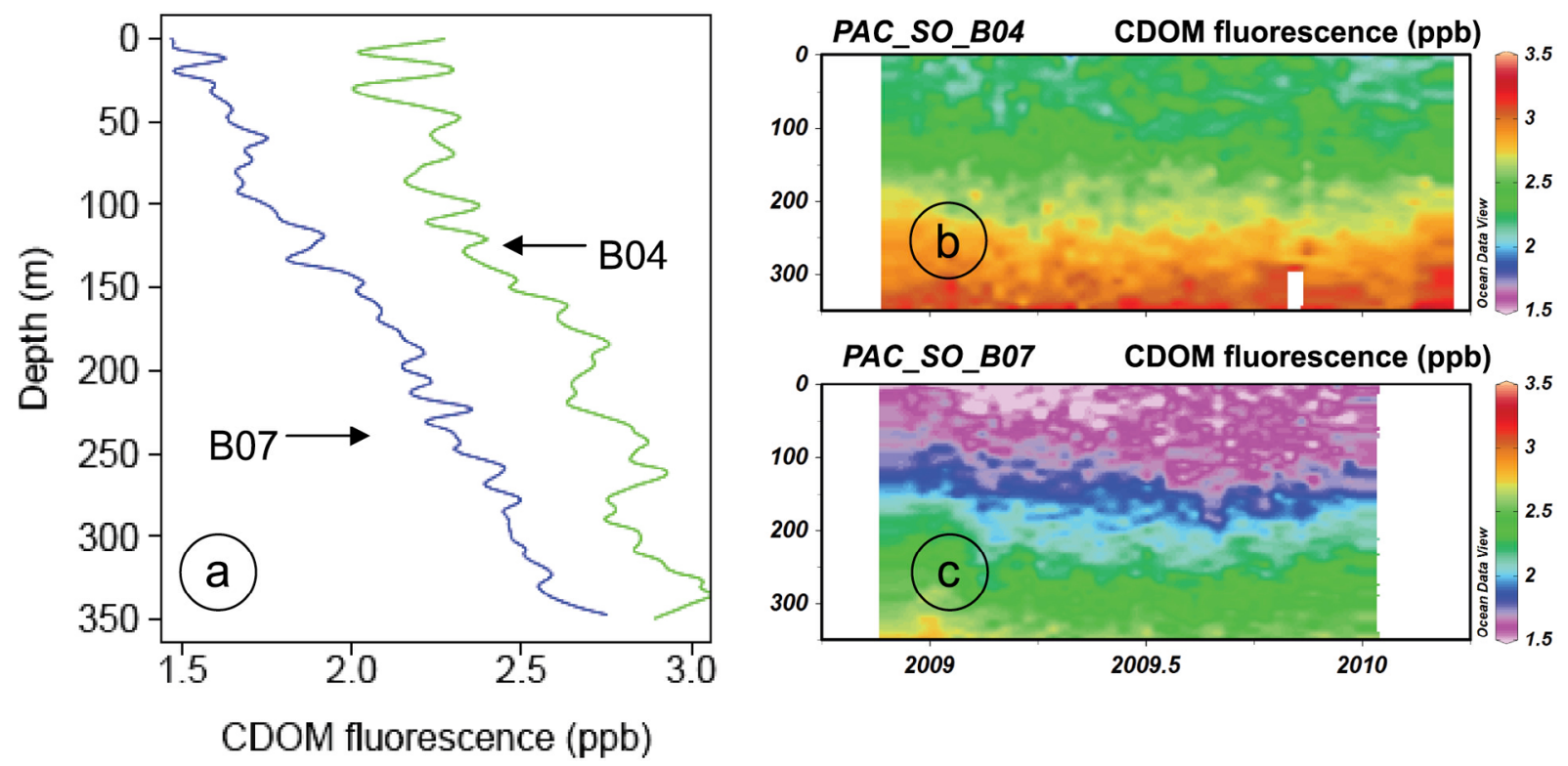

Figure 4. (a) A couple of CDOM fluorescence profiles (in parts per billion) acquired by two floats (B04 and B07) at the same location in the South Pacific $\left(27.19^{\circ} \mathrm{S} ; 109.88^{\circ} \mathrm{W}\right)$ and on the same day (3 December 2008, cycle 0 around 19:00 GMT). (b and c) Vertical sections showing the CDOM signals recorded by the two floats over their entire lifetime.

the scale factors provided on the characterization sheets, such intercept values are equivalent to $\sim 13$ to 48 counts, that is, equivalent to $\sim 30 \%$ to $100 \%$ of the nominal dark counts (between 30 and 50 counts, which were already subtracted from the measured signals). This would mean that either the dark currents estimated by the manufacturer were wrong (actually underestimated), or they would have (inexplicably) drifted between laboratory calibration and field deployment. Alternatively, and more probably, the initial calibrations were erroneous, especially with respect to the zero position within the concentration scale, (perhaps as an artifact owing to nonnegligible Raman emission, ignored in the calibration process). With the present regression based technique, the intercepts are anyway detected and can be subtracted before using the fluorometric signals. An additional comment about the ppb-a linear relationships is suggested by the low value of their slope, which essentially results from the presently limited sensitivity of the sensors when operated in open ocean low-CDOM environments. With such slopes, the $\mathrm{a}_{\mathrm{y}}$ variations in each zone, that span
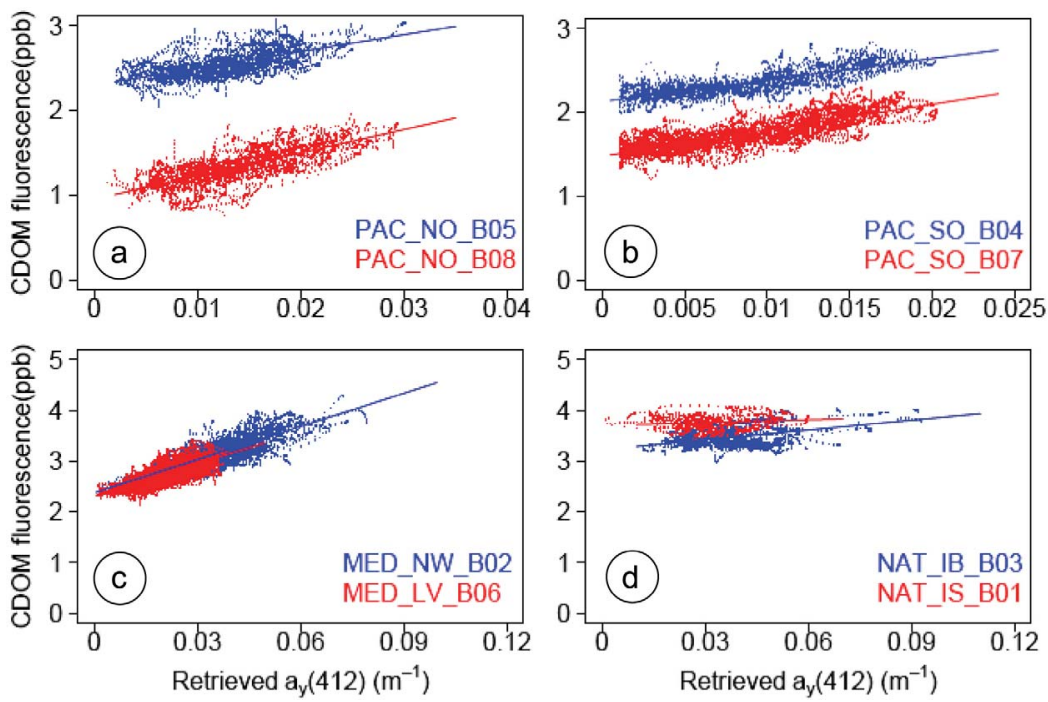

Figure 5. Plots of the CDOM fluorescence signal (units of parts per billion) versus retrieved CDOM absorption coefficient at $412 \mathrm{~nm}\left(\mathrm{~m}^{-1}\right)$ at the same depths and locations. Figures $5 \mathrm{a}, 5 \mathrm{~b}, 5 \mathrm{c}$, and $5 \mathrm{~d}$ are for the floats in the North Pacific, the South Pacific, the Mediterranean Sea, and the North Atlantic, respectively. The regression lines for each float are also plotted (see Table 2 for associated statistics). 
Table 2. Linearly Regressed Equations Between the Retrieved $a_{y}(412)$ Values and CDOM Fluorescence Signals ${ }^{\mathrm{a}}$

\begin{tabular}{lcccc}
\hline \multicolumn{1}{c}{ Float } & \multicolumn{1}{c}{ Regressed Equations } & $\mathrm{r}^{2}$ & $\mathrm{~N}$ & $\mathrm{z}_{\text {lim }}(\mathrm{m})$ \\
\hline PAC_NO_B05 & $\mathrm{a}_{\mathrm{y}}(412)=0.050\left(\mathrm{f}_{\mathrm{CDOM}}-2.299\right)$ & 0.404 & 3243 & $115-145$ \\
PAC_NO_B08 & $\mathrm{a}_{\mathrm{y}}(412)=0.037\left(\mathrm{f}_{\mathrm{CDOM}}-0.951\right)$ & 0.531 & 3348 & $100-144$ \\
PAC_SO_B04 & $\mathrm{a}_{\mathrm{y}}(412)=0.039\left(\mathrm{f}_{\mathrm{CDOM}}-2.129\right)$ & 0.640 & 2893 & $165-207$ \\
PAC_SO_B07 & $\mathrm{a}_{\mathrm{y}}(412)=0.032\left(\mathrm{f}_{\mathrm{CDOM}}-1.478\right)$ & 0.656 & 5537 & $156-214$ \\
MED_NW_B02 & $\mathrm{a}_{\mathrm{y}}(412)=0.046\left(\mathrm{f}_{\mathrm{CDOM}}-2.377\right)$ & 0.655 & 6264 & $41-66$ \\
MED_LV_B06 & $\mathrm{a}_{\mathrm{y}}(412)=0.047\left(\mathrm{f}_{\mathrm{CDOM}}-2.309\right)$ & 0.524 & $70-113$ \\
NAT_IB_B03 & $\mathrm{a}_{\mathrm{y}}(412)=0.155\left(\mathrm{f}_{\mathrm{CDOM}}-3.226\right)$ & 0.226 & 2525 & $24-50$ \\
NAT_IS_B01 & $\mathrm{a}_{\mathrm{y}}(412)=0.533\left(\mathrm{f}_{\text {CDOM }}-3.700\right)$ & 0.021 & 934 & $25-55$ \\
\hline
\end{tabular}

${ }^{\mathrm{a}}$ Retrieved $\mathrm{a}_{\mathrm{y}}(412)$ values are in $\mathrm{m}^{-1} ; \mathrm{f}_{\mathrm{CDOM}}$ values are in parts per billion. The number of pairs of data used in each regression computation, as well as the associated $\mathrm{r}^{2}$ values, are provided; $Z_{\lim }$ are the maximal depths allowing the $\mathrm{E}_{\mathrm{d}}(412)$ irradiance profiles to be captured (depending on season and water clarity); therefore the $\mathrm{K}_{\mathrm{d}}(412)$ determinations and thus $\mathrm{a}_{\mathrm{y}}(412)$ derivations are limited to these depths.

about one order of magnitude, are only reflected by variations within about one $\mathrm{ppb}$ in the fluorescence response. As already said, the worst situation is for these instruments deployed in the North Atlantic. The data of these floats will be displayed for the sake of completion but not be discussed further.

\section{Results and First Comments}

\subsection{Application of the Method to Radiometric and Fluorometric Floats Data}

[24] The first example deals with the two floats (B05 and B08) in the North Pacific (Figure 6). The linear fits shown in Figure 5a (equations in Table 3) were used to transform the ppb values into absorption values at $412 \mathrm{~nm}$. Vertical distributions of the $\mathrm{a}_{\mathrm{y}}(412)$ coefficient retrieved from the two floats are consistently similar over the lapse of time they have in common, and despite an increasing distance between them (see trajectories in http://www.obs-vlfr.fr/OAO). The results are displayed in Figure 6 where the vertical scales correspond to the depth interval $(0$ down to $350 \mathrm{~m})$ of acquisition of fluorometric data. The data of the two floats which were so differing in terms of ppb (essentially because of differing intercepts; see Figure 5a) are reconciled after calibration. The vertical CDOM distributions during the first months (i.e., when the floats remained close) are nicely coinciding, with values ranging between 0.01 and $0.04 \mathrm{~m}^{-1}$,
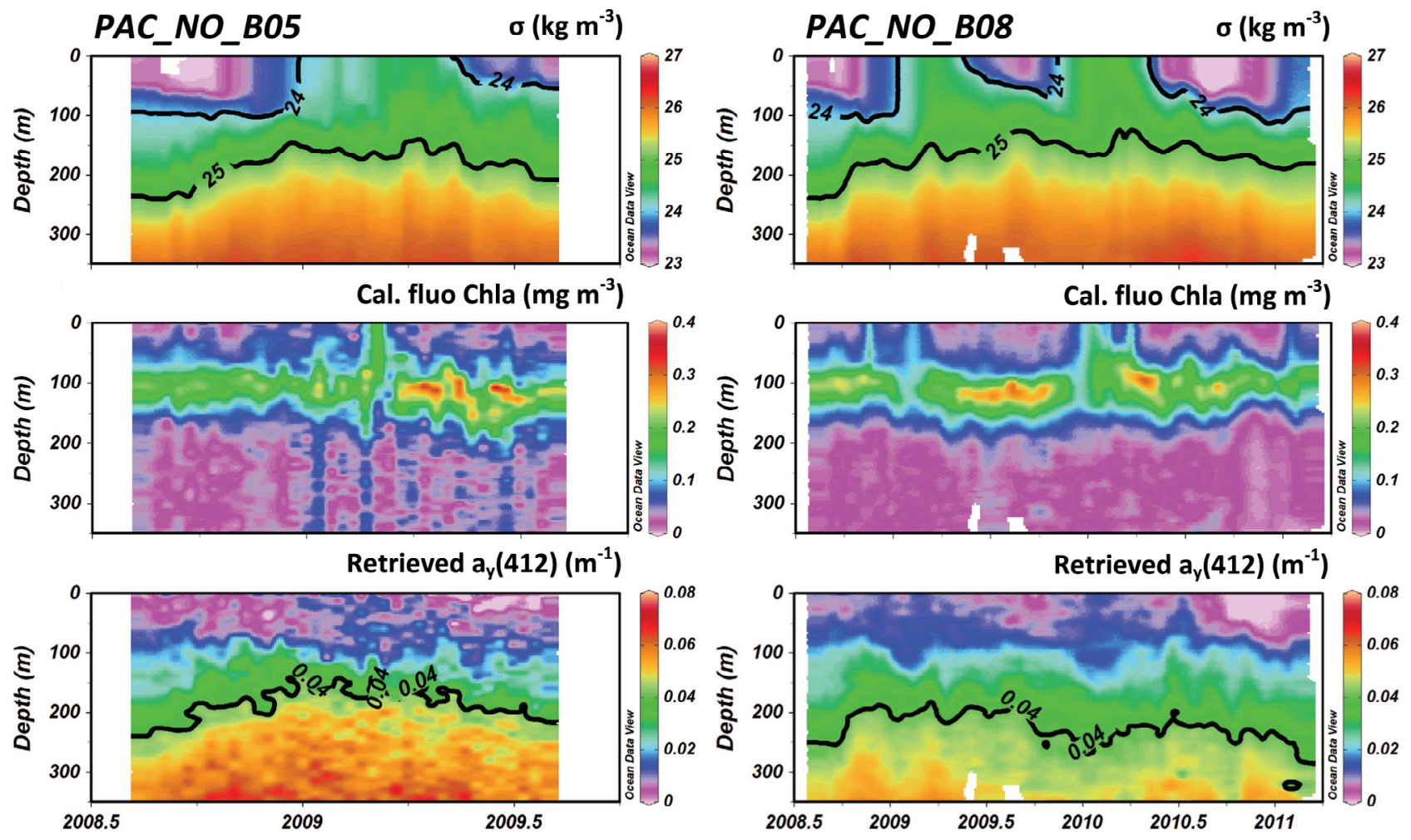

Figure 6. Results for the North Pacific sector; for each float, three panels are presented. They provide (top to bottom) vertical sections (0-350 m) of density, calibrated [Chla], and CDOM absorption coefficient, as derived from the fluorometric data after calibration. Note that the time scales are adjusted on the lifetime of each float and differ accordingly. 
Table 3. Mean Value of $\mathrm{a}_{\mathrm{y}}(412)$ at the Parking Depth Computed Over the Entire Lifetime of Each Float and Corresponding Standard Deviation $^{\mathrm{a}}$

\begin{tabular}{lc}
\hline \multicolumn{1}{c}{ Float } & $\begin{array}{c}\text { Mean a }(412) \text { at the } \\
\text { Parking Depth }\left(\mathrm{m}^{-1}\right) \pm \text { Standard Deviation }\end{array}$ \\
\hline PAC_NO_B05 & $0.1150 \pm 0.0040$ \\
PAC_NO_B08 & $0.0955 \pm 0.0038$ \\
PAC_SO_B04 & $0.0585 \pm 0.0012$ \\
PAC_SO_B07 & $0.0521 \pm 0.0023$ \\
MED_NW_B02 & $0.0489 \pm 0.0003$ \\
MED_LV_B06 & $0.0456 \pm 0.0012$ \\
NAT_IB_B03 & $0.1060 \pm 0.0014^{\mathrm{b}} ; 0.1870 \pm 0.0047^{\mathrm{c}}$ \\
NAT_IS_B01 & $0.2180 \pm 0.0054$ \\
\hline
\end{tabular}

${ }^{\text {a }}$ Parking depth is $1000 \mathrm{~m}$.

${ }^{b}$ When the float was in the Icelandic basin.

${ }^{c}$ When the float was in the Norwegian Sea.

between surface and $\sim 200 \mathrm{~m}$, and reaching $\sim 0.07 \mathrm{~m}^{-1}$ at $350 \mathrm{~m}$.

[25] On the basis of the regression analyses shown in Figure 5b, the data of the pair of floats (B04 and B07) in South Pacific provide the retrieved $\mathrm{a}_{\mathrm{y}}(412)$ values displayed on Figure 7. Compared to those in the North Pacific, these values are notably lower. Indeed, they range from less than 0.005 to $0.015 \mathrm{~m}^{-1}$ within an extended upper layer $(0-150 \mathrm{~m})$, and do not exceed $0.045 \mathrm{~m}^{-1}$ at depth $(350 \mathrm{~m})$. This northsouth difference in yellow substance content is consistent with what was previously inferred from satellite (ocean color) observations for the upper layer [Morel et al., 2010].

[26] On the basis of the regressions shown in Figure 5c, the vertical profiles of CDOM absorption in the Mediterranean Sea are displayed as a function of time in Figure 8.

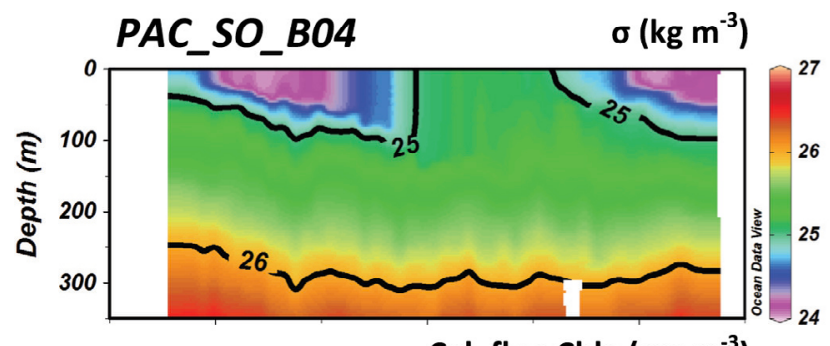

Cal. fluo Chla $\left(\mathrm{mg} \mathrm{m}^{-3}\right)$

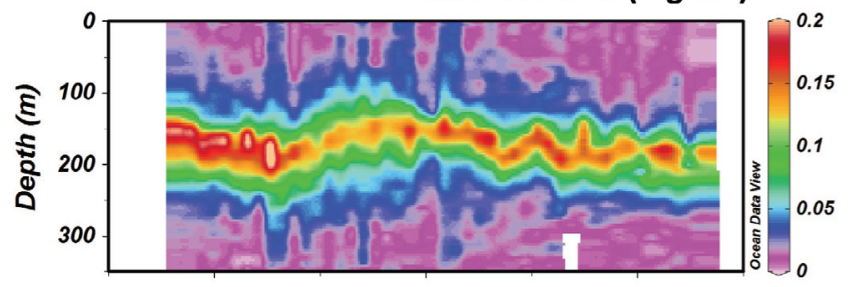

Retrieved $a_{y}(412)\left(m^{-1}\right)$

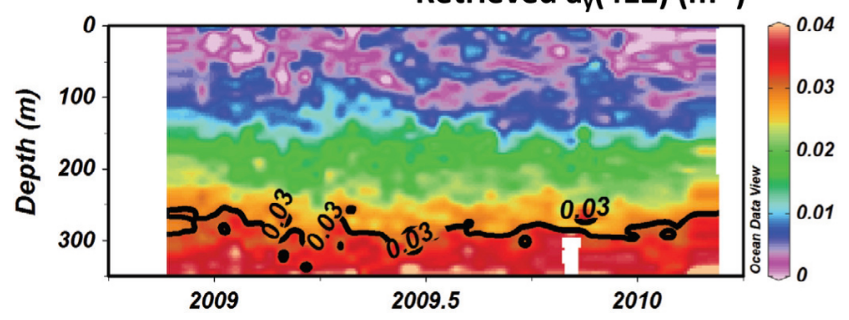

Considerable differences can be noted between the two Mediterranean basins, with systematic larger $\mathrm{a}_{\mathrm{y}}(412)$ values, whatever the depth, in the western basin; this difference was already observed for the upper layer [Morel and Gentili, 2009b].

[27] Applying the same kind of interpretation to the data collected in the North Atlantic is problematic (Figure 9), as the translation of ppb indices into CDOM absorption coefficients remains uncertain. Anyway, these few determinations tend to demonstrate that the near surface $a_{y}(412)$ values are distinctly higher than those observed in all other (Pacific and Mediterranean Sea) areas. Despite a restricted range of variation in $\mathrm{ppb}$, some organized CDOM patterns appear on the vertical sections down to $350 \mathrm{~m}$ (Figure 9).

\subsection{CDOM Regional and Vertical Distribution}

[28] Even if the present work is a methodology-oriented work, it is appropriate to briefly examine the above results in a more general context involving physical and biogeochemical aspects. Such an examination is also an indirect way of qualitatively testing the quality of the CDOM processing to the extent that some spatial and temporal coherencies between density field, phytoplankton presence and CDOM concentration are expected. Indeed, there is no CDOM field data available for a direct validation in these zones where the floats have been operated. Ocean color observation from space can also allow CDOM contents to be estimated in terms of absorption. This possibility, though restricted to the near surface layer, will also be examined (3.3).

[29] The following comments are made zone by zone and refer to Figures 6, 7, 8, and 9. Beside the CDOM panels, already discussed, are also displayed vertical sections of

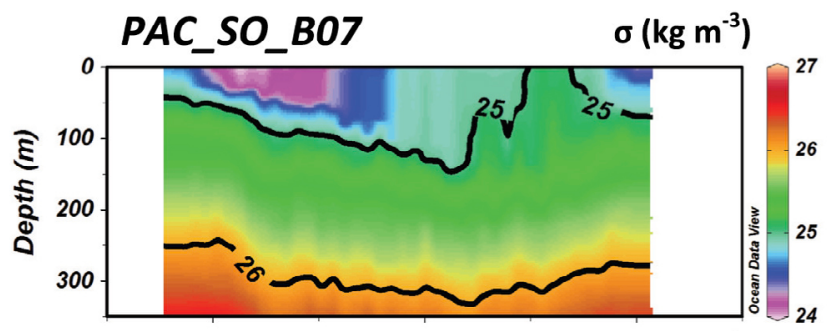

Cal. fluo Chla ( $\left.\mathrm{mg} \mathrm{m}^{-3}\right)$
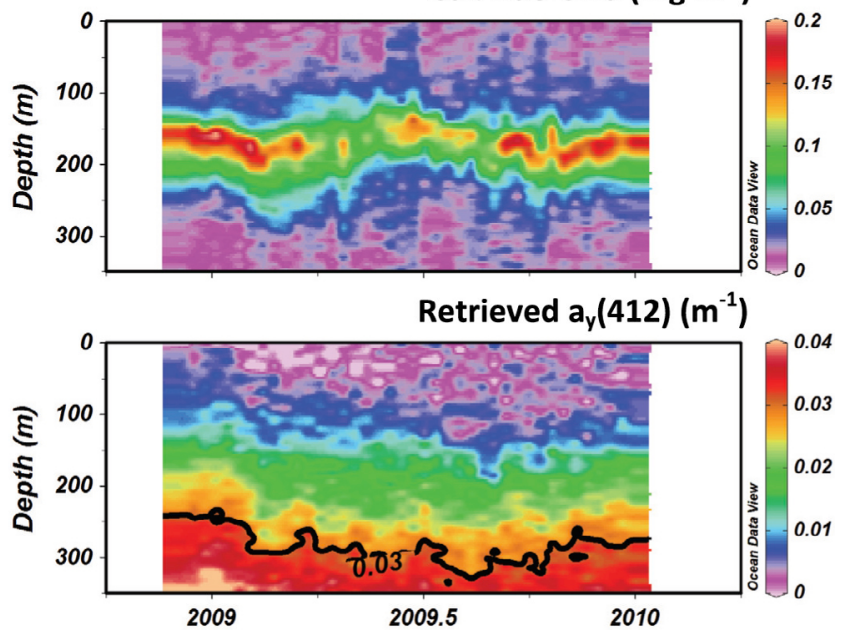

Figure 7. Same as Figure 6, but for the two floats in the South Pacific sector; note that the color scales differ from those used in Figure 6. 


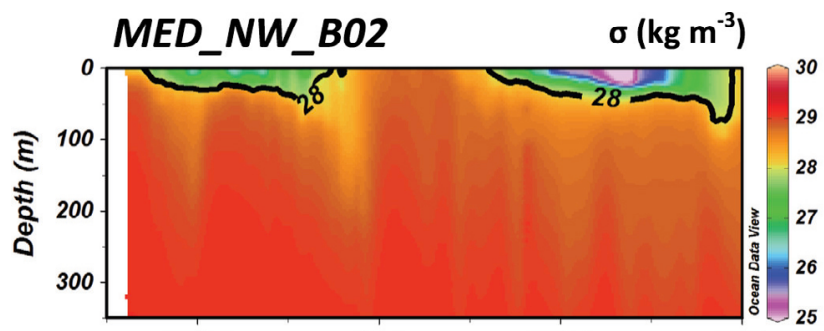

Cal. fluo Chla ( $\mathrm{mg} \mathrm{m}^{-3}$ )

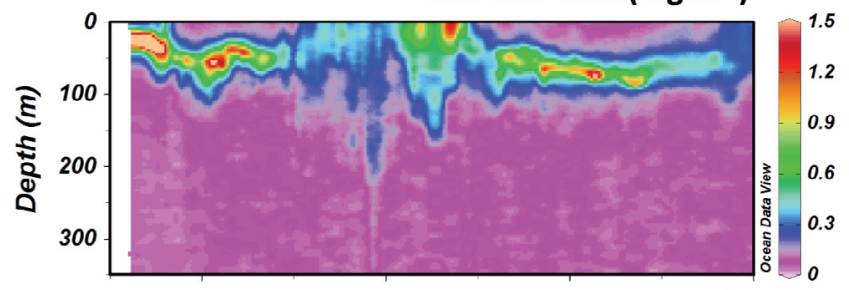

Retrieved $a_{y}(412)\left(m^{-1}\right)$

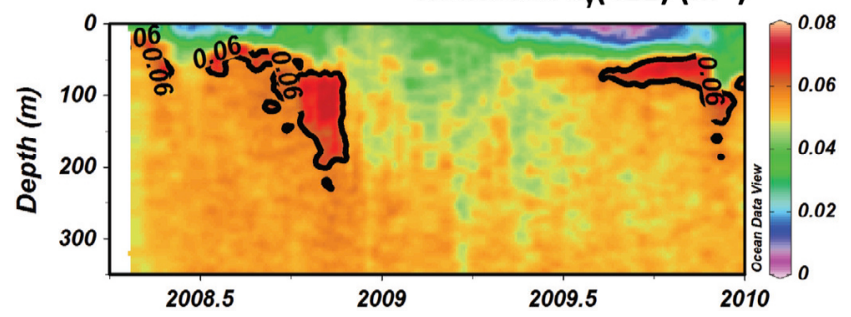

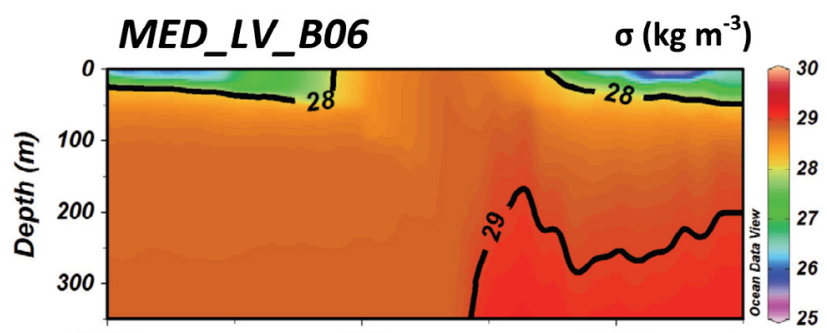

Cal. fluo Chla $\left(\mathrm{mg} \mathrm{m}^{-3}\right)$

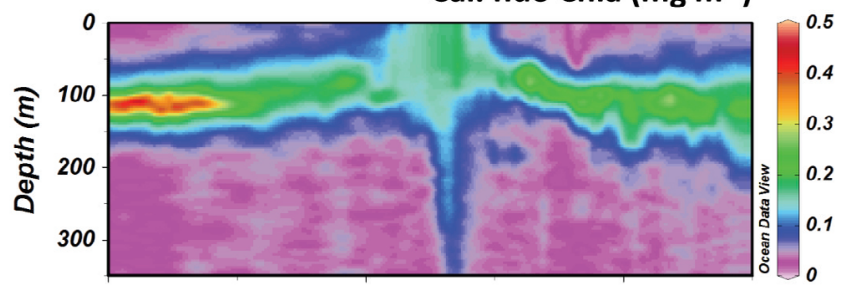

Retrieved $a_{y}(412)\left(m^{-1}\right)$

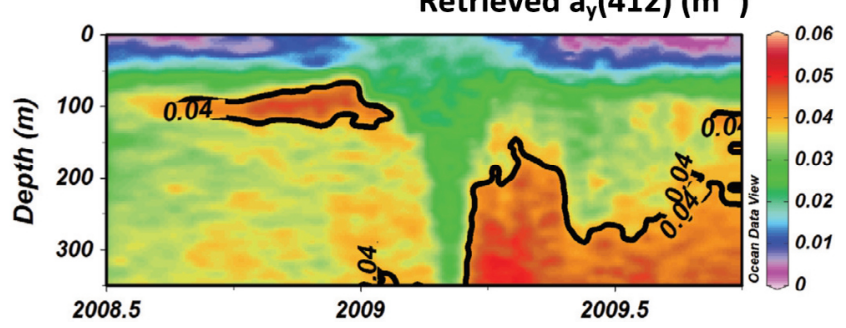

Figure 8. Same as Figures 6 and 7, but for the two floats in the Mediterranean Sea; note that the color scales differ from those used in Figures 6 and 7; they also differ for the eastern and western Mediterranean basins.

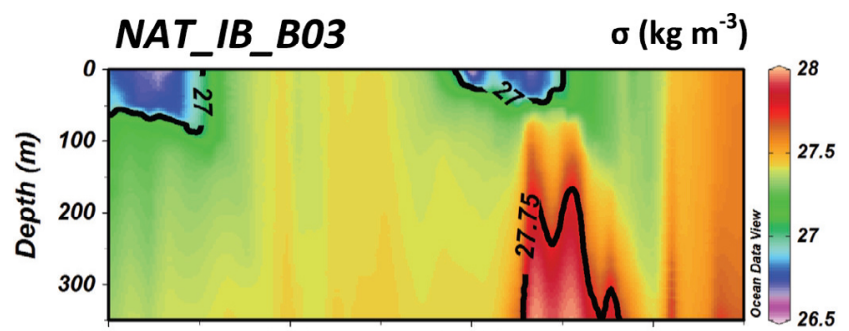

Cal. fluo Chla $\left(\mathrm{mg} \mathrm{m}^{-3}\right)$
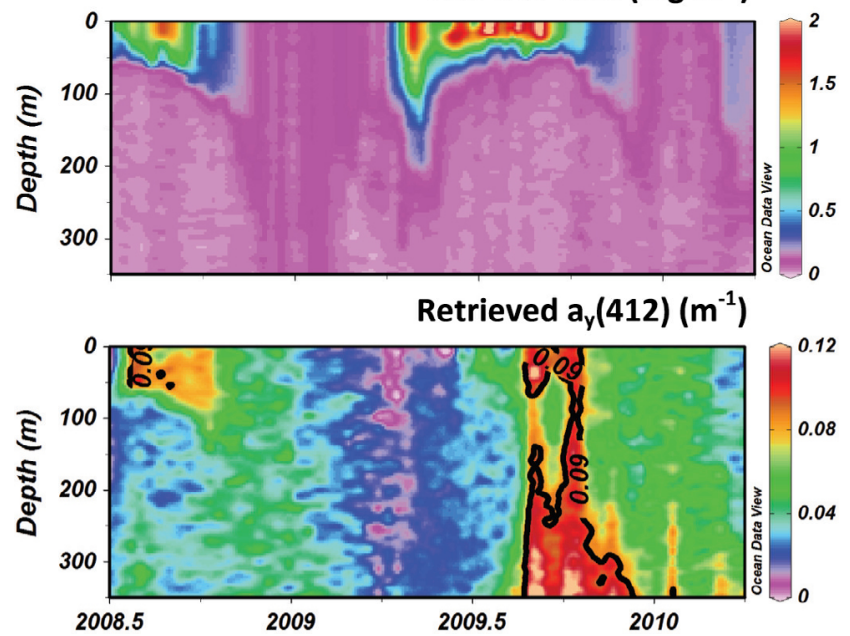

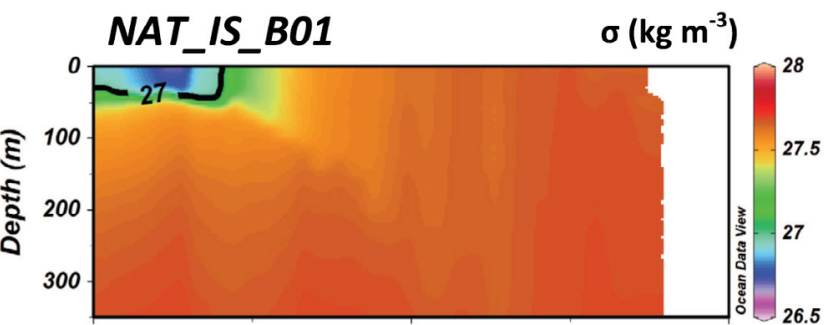

Cal. fluo Chla ( $\mathrm{mg} \mathrm{m}^{-3}$ )
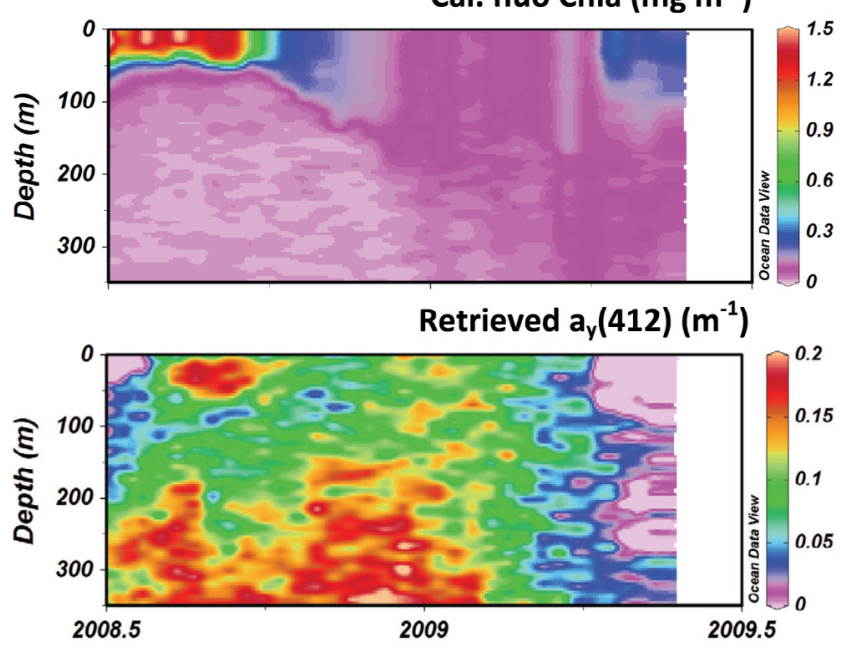

Figure 9. Same as Figures 6, 7, and 8, but for the two floats in the northern Atlantic; note also the changes in color scales. 
density excess $\left(\sigma, \mathrm{kg} \mathrm{m}^{-3}\right)$, computed with the temperature and salinity records, and of $[\mathrm{Chla}]$ values $\left(\mathrm{mg} \mathrm{m}^{-3}\right)$ derived from [Chla] fluorometry, according to the method described in the work of Xing et al. [2011].

[30] In the North Pacific, the two floats (B05 and B08) provide very similar results for all parameters. The deep chlorophyll maximum (DCM), is weakly varying in intensity, and steadily located at $100-120 \mathrm{~m}$. The CDOM content is distinctly affected near the surface by photobleaching that mainly occurs in summer (and coincides with higher temperature and lower density within the near surface layer). The CDOM distribution does not exhibit any notable feature other than a regular increase with depth, which starts at the DCM level. From less than $0.01 \mathrm{~m}^{-1}$ in upper layers, $\mathrm{a}_{\mathrm{y}}(412)$ exceeds $0.04 \mathrm{~m}^{-1}$ beyond 200-250 m (with $\sigma>$ $\left.25 \mathrm{~kg} \mathrm{~m}^{-3}\right)$. At the parking depth $(1000 \mathrm{~m})$, the value is steadily around $0.1 \mathrm{~m}^{-1}$ (see Table 3 ).

[31] The results of the two floats in South Pacific (B04 and B07; see Figure 7) are also close. The vertical structures resemble those in North Pacific, yet with systematically lower CDOM and [Chl $a]$ values. These values are associated with particularly deep DCM (160-200 m); such unusual DCM levels, as well as extremely low [Chla] values in the upper layers, were already observed during the BIOSOPE cruise in the same zone [Ras et al., 2008]. As in the northern sector, the CDOM and [Chla] contents are rather stable; the gradient for the CDOM increase $\left(\mathrm{a}_{\mathrm{y}}(412)>0.02 \mathrm{~m}^{-1}\right.$ at about $150 \mathrm{~m}$ ) is apparently related to the DCM position; at $1000 \mathrm{~m}$ deep, $\mathrm{a}_{\mathrm{y}}(412)$ is about $0.055 \mathrm{~m}^{-1}$ (Table 3). The CDOM bleaching, encompassing a $\sim 100 \mathrm{~m}$ thick layer (see also Figure 2 for its central portion), appears to be a permanent process, without significant seasonal signal.

[32] The situation observed by the float B06 in the eastern Mediterranean basin, exhibits likeliness with that in North Pacific, in regard to its CDOM content, $[\mathrm{Chl} a]$ values, and position of the DCM (at about $100 \mathrm{~m}$ ). The depressive effect in summer of the photobleaching process within the surface layer is more marked in eastern Mediterranean. Below this layer, the $\mathrm{a}_{\mathrm{y}}$ increase is remarkably abrupt and the corresponding gradients are stronger and shallower than those observed in Pacific. The important difference results from the existence here of a conspicuous winter vertical mixing, which breaks the DCM in early March, triggers a (moderate) spring bloom in the surface layer, and simultaneously brings back into this layer some unbleached CDOM. Correlatively, a CDOM decrease in the deeper layers results from dilution with surface waters. A similar phenomenon owing to subduction of yellow substance depleted surface waters was already described in the Sargasso Sea [Nelson et al., 2007]. The sudden change in April 2009 (for both $\sigma$ and CDOM content) within the deep layers is a consequence of an abrupt change of water mass encountered by the float (see trajectory in http://www.obs-vlfr.fr/OAO); indeed, this float remained inside an eddy during 9 months, before escaping in April). Not observed in the Pacific zone, a link seems to exist in late autumn between a localized relative increase in CDOM (around $100 \mathrm{~m}$, at the DCM level) and the DCM weakening.

[33] With respect to the vertical structure and temporal evolution, the main difference between the western and eastern basins (Figure 8) lies in a general enhancement of the CDOM values, ranging between $\sim 0.02$ and $0.06 \mathrm{~m}^{-1}$ in the western basin, versus $\sim 0.01$ to $0.05 \mathrm{~m}^{-1}$ in the eastern basin; the deep values (at $1000 \mathrm{~m}$ ) are similar, about $0.047 \mathrm{~m}^{-1}$; see Table 3). Actually, the [Chla] values are also notably higher in the western basin, with a shallower DCM (around 50 $60 \mathrm{~m}$ ). The winter vertical mixing in this basin has the same results as in the eastern basin regarding the [Chla] and $\mathrm{CDOM}$ vertical distributions. A comment also valid for both basins is the existence of a link between the DCM and a local CDOM increase, not in phase with the [Chl $a]$ maximum, but slightly shifted by about two months, that is, when the DCM starts to vanish.

[34] The highest [Chla] and CDOM values detected with the present floats are those observed in North Atlantic. The strong perturbation (B03 float), which affects both the density and the CDOM fields in September 2009, is related to the trajectory of this float leaving the Icelandic basin and entering the Norwegian Sea above the Iceland-Faeroe rise. An abrupt change in the deep $\mathrm{a}_{\mathrm{y}}$ value also occurs at $1000 \mathrm{~m}$, with an increase from $\sim 0.11$ to $0.19 \mathrm{~m}^{-1}$ (Table 3).

\subsection{Comparison Floats/MODIS Data}

[35] With the last reprocessing of the SeaWiFS and MODIS-A data, NASA has routinely produced and distributed under the name "CDOM index," the factor $\Phi$. This factor was introduced [Morel and Gentili, 2009a] to account for the variability around the mean relationship established between yellow substance and [Chla] contents in oceanic case 1 waters and for the upper layer. At the wavelength $412 \mathrm{~nm}, \mathrm{a}_{\mathrm{y}}(412,[\mathrm{Chl}$ ] $]$ ) is expressed as [Morel and Gentili, 2009a]

$$
\mathrm{a}_{\mathrm{y}}(412,[\mathrm{Chl} a])=\Phi 0.0524[\mathrm{Chl} a]^{0.63}
$$

The mean relationship is represented by equation (15) when $\Phi \equiv 1$, and is modified by the factor $\Phi$ that may be larger or lesser than unity, indicating an "excess" or a "deficit" of yellow substance compared to its mean value for a given $[\mathrm{Chl} a]$ value. By simultaneously using $\Phi$ and [Chla], produced for the same pixel, it is therefore possible to compute the CDOM absorption coefficient, $\mathrm{a}_{\mathrm{y}}(412)$.

[36] Comparing $\mathrm{a}_{\mathrm{y}}$ values as derived in the same location from space observations and from floats provides a test of consistency, without being a true validation; indeed, a true validation would imply in situ (i.e., "sea truth") measurements. For MODIS-A, the OC3M algorithm [O'Reilly et al., 2000] is used to derive [Chla]. Conversely to what is mistakenly said in the work of Morel and Gentili [2009b], this $[\mathrm{Chl} a]$ value has to be "corrected" to account for the fact that $\Phi$ may differ from 1, while the standard OC3M algorithm tacitly implies that $\Phi=1$. The way of correcting [Chla] has been outlined by Morel and Gentili [2009b, Figure 9] and its associated polynomial. NASA also makes available the $a_{d g}(443)$ product (i.e., the absorption coefficient at $443 \mathrm{~nm}$ by the colored detrital and dissolved material (CDM)) as obtained via the GSM ocean color model [Garver and Siegel, 1997; Maritorena et al., 2002]. Inasmuch as absorption by the dissolved material predominates [Siegel et al., 2002], $\mathrm{a}_{\mathrm{dg}}$ is practically equivalent to the $\mathrm{a}_{\mathrm{y}}$ coefficient obtained via $\Phi$ and $[\mathrm{Chl} a]$. The $\mathrm{a}_{\mathrm{dg}}(443)$ coefficient can be transferred toward $412 \mathrm{~nm}$, simply by multiplying by a factor equal to 1.75 , an average value $( \pm 0.15)$ in correspondence with a mean spectral slope, $\mathrm{S}\left(=-0.018 \pm 0.003 \mathrm{~nm}^{-1}\right)$ of 

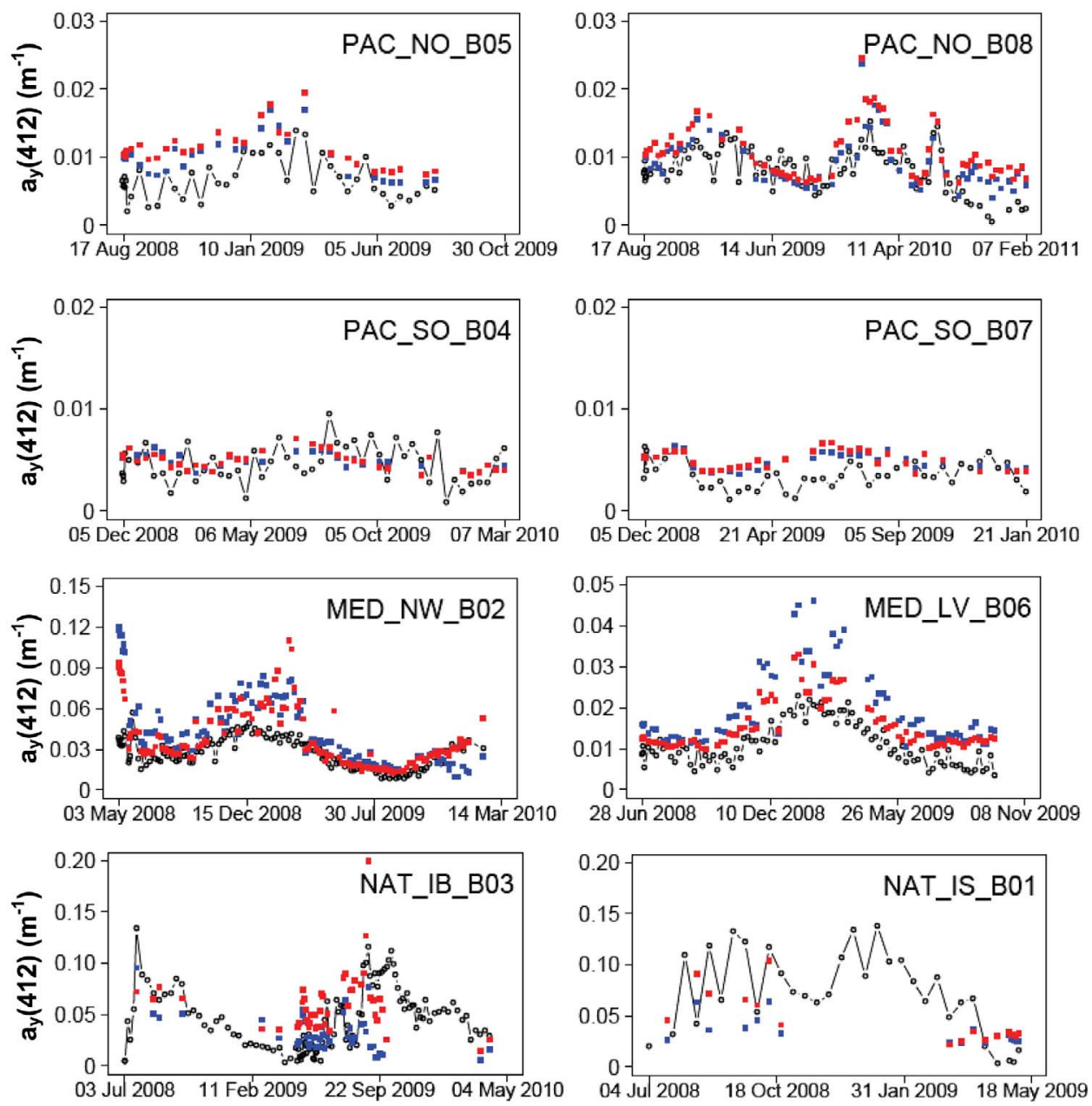

Figure 10. Comparison between the CDOM absorption coefficient (at $412 \mathrm{~nm}$ ) within the upper layer as retrieved from the floats information (black circles) and the same coefficients as derived from Ocean Color (MODIS-A) data via $\Phi$ and [Chla] (blue squares) and via the GSM method (red squares), respectively. Note that the $\mathrm{a}_{\mathrm{y}}$ scales differ between the various panels and zones.

the exponential decay of the yellow substance absorption. Therefore, another comparison between satellite and float data is also possible.

[37] MODIS-A level 3 composites ( 8 days, $9 \mathrm{~km} \times 9 \mathrm{~km}$ ) are used to find match up with the float data. The $\Phi$ and [Chla] available information, as well as the $\mathrm{a}_{\mathrm{dg}}$ values, are averaged over a $\sim 0.2^{\circ} \times 0.2^{\circ}$ box centered on the location where the float has emerged. The spatial and temporal ( 4-6 pixels; one week) window is thus rather wide, which is believed to be licit according to slow changes observed in the time series of the properties studied. With such wide windows, the number of possible coincidences is maximized; yet it remains restricted by cloudiness. Thanks to generally favorable sky conditions, the number of realized matchup is high in Mediterranean; in contrast, it is deceptively low in the North Atlantic zones.

[38] The time series (Figure 10) shows the upper layer CDOM absorption, either derived from the floats, or derived from the MODIS-A imager (via the GSM and via $\Phi-[\mathrm{Chl} a]$ methods). A general agreement does exist between in situ and space determinations of CDOM absorption with respect to magnitude and seasonality. The lowest $\mathrm{CDOM}$ values $\left(\mathrm{a}_{\mathrm{y}}<0.005 \mathrm{~m}^{-1}\right)$ are those observed in the South Pacific. In contrast, about 10 times larger $\mathrm{a}_{\mathrm{y}}$ values are found during winter in western Mediterranean. Except in winter (within eastern Mediterranean Sea), the $\mathrm{a}_{\mathrm{y}}(412)$ values obtained via $\Phi$ or via GSM, are generally close, which was also the result of previous systematic comparisons [Morel and Gentili, 2009a] and does not deserve more comments here.

[39] The absence of seasonal signal near Easter Island (South Pacific) seems to contradict the results of another study, also based on satellite observation [Morel et al., 2010]. Yet, the surface area inside which the floats have drifted is much more restricted (by a factor of 10) than the one considered in the cited study. Actually, the two floats remained within the core of a permanent anticyclonic circulation, steadily exhibiting hyperoligotrophic conditions. Near Hawaii in North Pacific, the $\mathrm{a}_{\mathrm{y}}$ winter maximum, is well described by both floats and MODIS-A. Note that such a seasonality was not observed [Morel et al., 2010] in a wide 


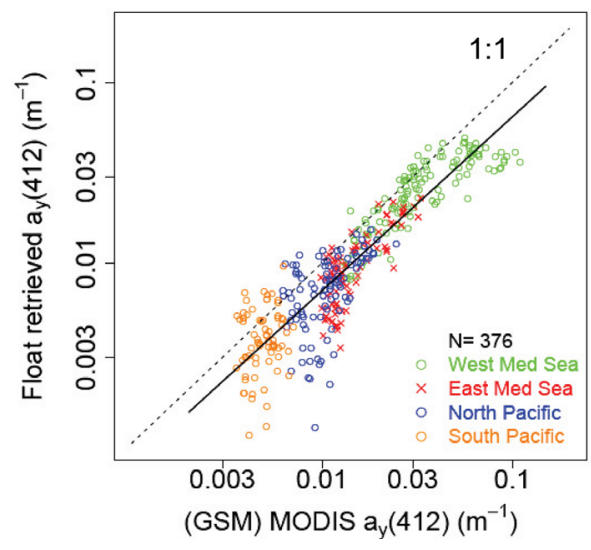

Figure 11. CDOM absorption coefficient at $412 \mathrm{~nm}$ within the upper layer as retrieved from the floats (replotted from Figure 10) versus the same quantity as retrieved from MODIS-A data through the use of GSM method.

zone located southward, at about $1300 \mathrm{~km}$ from the Hawaiian Archipelago.

[40] For the Mediterranean Sea, the seasonal cycles and differences in CDOM content between the two basins, as previously observed (by using SeaWiFS data) [Morel and Gentili, 2009b] are globally confirmed by the present float and MODIS-A data. However, a close comparison points out frequent overestimations of $a_{y}$ in winter from space data, when $\mathrm{a}_{\mathrm{y}}$ experiences its maximum.

[41] A global comparison between the float and (GSM) MODIS-A data is provided by the scatterplot in Figure 11. The low $\mathrm{a}_{\mathrm{y}}$ values detected by the floats (Pacific) are not reproduced in GSM outputs (no GSM values below $0.04 \mathrm{~m}^{-1}$ ). In general, the fluorescence based data are slightly below those retrieved from space (by about $30 \%$, with $\mathrm{r}^{2}=0.78$ ). A plot based on $\mathrm{a}_{\mathrm{y}}$ values derived from the $\Phi$ index, instead of GSM, leads to similar conclusions.

\subsection{Chlorophyll and CDOM Retrievals}

[42] The coherency of the CDOM and [Chla] retrievals from their dedicated fluorometric sensors and associated processing methods can be directly assessed in reference to equation (15) (established for the upper layer). On Figure 12 are plotted the $\mathrm{a}_{\mathrm{y}}(412)$ values retrieved from the floats (those displayed on Figure 10 as black symbols) versus the upper layer [Chla] values simultaneously obtained in the same locations with the fluorometric sensors. There is a rough covariation of both $[\mathrm{Chl} a]$ and CDOM quantities, as expected [e.g., Siegel et al., 2002; Morel and Gentili, 2009a]. By recalling that the estimate of $\mathrm{a}_{\mathrm{y}}(412)$ has made use of the local [Chla] value (equation (13)), the two quantities are not strictly independent. It is only partially true, since a degree of liberty still exists that is represented by the factor $\Phi$ (equation (15)). In agreement with the results of previous studies [Lee and Hu, 2006; Morel et al., 2010], the data for the tropical North and South Pacific are roughly brought into alignment with the relationship expressed by equation (15) when $\Phi \sim 1$. Another study based on SeaWiFS data showed that $\Phi$ is generally above 1 for the Mediterranean Basins [Morel and Gentili, 2009b].
The present $\mathrm{a}_{\mathrm{y}}$ data, systematically above the line corresponding to $\Phi=1$, corroborate this previous finding.

\section{Discussion and Conclusions}

\subsection{Error Analysis}

[43] The use of equation (9) to retrieve $a_{y}(412)$ deserves some examination in particular with regard to the expected accuracy. It is assumed that the $\mathrm{E}_{\mathrm{d}}(412)$ profile is accurately measured, so that the $\mathrm{K}_{\mathrm{d}}(412)$ coefficient is precisely determined. A major expected uncertainty results from the resort to the empirical equation (5b) together with a $[\mathrm{Chl} a]$ value, to provide a modeled $a_{p}(412)$, then inserted into equation (9). The Root Mean Square Error (RMSE) calculated in $\log _{10}$ space for $a_{p}(412)$ amounts to 0.168 ; therefore, an actual $a_{p}$ value may diverge from the modeled value by about $35 \%$ ( $+47 \%$ or $-32 \%$, within \pm 1 standard deviation). This RMSE in the $\mathrm{a}_{\mathrm{p}}-[\mathrm{Chl} a]$ relationship (besides experimental errors) accounts for the natural variability in particulate absorption, actually in the living algae-to-inanimate detrital particles ratio, and in the packaging effect and pigmentation within the algal cells. According to equation (9), this RMSE affecting $a_{p}$ is integrally transferred (with an opposite sign) onto the $\mathrm{a}_{\mathrm{y}}$ estimate.

[44] The second source of uncertainty lies in the estimate of [Chla], also inserted in equation (9), which does not derive from an accurate chemical analysis as for equation (5b), but from an estimate based on the Chla fluorescence profiles and downward irradiance $\mathrm{E}_{\mathrm{d}}(490)$. The variability of the fluorescence yield was studied by Cullen [1982] and results in a lack of strict correlation between Chla fluorescence and [Chla]. Uncertainties attached to [Chla] retrievals from the fluorescence and irradiance $\left(E_{d} 490\right)$ signals provided by the floats were thoroughly analyzed in the work of Xing et al. [2011, Figure 9] by comparing fluorescence derived [Chla] values with HPLC determinations made on contemporaneous discrete samples. The agreement is generally good, with

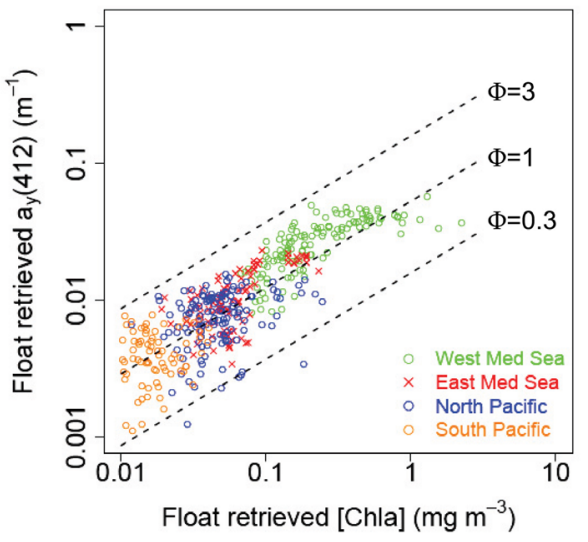

Figure 12. CDOM absorption coefficient at $412 \mathrm{~nm}$ retrieved from the floats information (replotted from Figure 10) within the upper layer as a function of the chlorophyll concentration retrieved at the same locations from the Chl-fluorometric sensors. The straight lines in this log-log plot correspond to equation (9b), with three values given to parameter $\Phi$. 
no significant bias. The scatter of the paired data, however, is rather high, particularly for very low [Chla] values $\left(<0.03 \mathrm{mg} \mathrm{m}^{-3}\right)$; within the $0.03-3 \mathrm{mg} \mathrm{m}^{-3}$ range, it leads to an uncertainty of about $\pm 40 \%$ (at $1 \mathrm{SD}$ ). This scatter has two origins (neglecting the small errors in the HPLC determinations). The variability in quantum yield is the first source of deviation; the second source is in the use of $\mathrm{K}_{\mathrm{d}}$ (at $490 \mathrm{~nm}$ ) for scaling the fluorescence response in terms of absolute [Chla]. This point deserves a special examination.

[45] The relationship between $K_{d}(490)$ and [Chla] is indeed affected, as soon as the CDOM-to-[Chla] ratio deviates from its mean value (as soon as $\Phi$ in equation (15) deviates from 1). The use of the measured $K_{d}$ with the average $\mathrm{K}_{\mathrm{d}}-[\mathrm{Chla}]$ relationship may thus lead to an overestimate (underestimate) of [Chla], if $\Phi$ is larger (lesser) than 1 (see also Morel and Gentili [2009a] for the importance of this effect). Together with the fluorescence yield variability, this possible inaccuracy contributes to the $\pm 40 \%$ variability mentioned above.

[46] When $\Phi$ differs from 1, there is also another impact, now on $K_{d}(412)$, used in equation (9). If, for instance CDOM is in excess $(\Phi>1)$, [Chla] derived via $\mathrm{K}_{d}(490)$ will be overestimated (up to $40 \%$, see above). When this overestimated [Chla] value is introduced as such in equation (9), the consequence is an overestimate of the particulate absorption term (up to $25 \%$, because of the presence of the exponent, 0.686). Therefore, that fraction of $\mathrm{K}_{\mathrm{d}}(412)$ due to CDOM (i.e., the term $1.3 \mathrm{a}_{\mathrm{y}}(412)$ ) will be accordingly underestimated. This inference would be strictly true if $K_{d}(412)$ was unchanged; yet $K_{d}(412)$ is also and proportionately increased by the actual presence of the "excess" of $\mathrm{CDOM}$; therefore, and owing to this counterbalancing effect, the resulting estimate of the term $1.3 \mathrm{a}_{\mathrm{y}}(412)$ remains essentially unaffected.

[47] Other potential uncertainties (resulting from approximations made about $\mu_{\mathrm{d}}$ and $\mathrm{b}_{\mathrm{bp}}$ ) are negligible compared to those above described. In summary, the uncertainty $( \pm 35 \%)$ on the $\mathrm{a}_{\mathrm{p}}(412)$ estimate, and the one on the conversion of chlorophyll fluorescence into [Chla] $( \pm 40 \%)$ are independent, and a priori they are additive and must be added. This realistic conclusion which corresponds to the worst situation may appear somewhat pessimistic; actually, the comparative data shown in Figure 3 tend to show that, case by case, the uncertainty is well of the order of that predicted. Such an inaccuracy is not at random as the visual inspection of the CDOM profiles does not reveal erratic patterns.

\subsection{Concluding Remarks and Perspectives}

[48] Chromophoric dissolved organic matter in the upper oceanic layer is detectable and quantifiable from space with ocean color sensors [Siegel et al., 2002; Brown et al., 2008; Fichot et al., 2008; Morel and Gentili, 2009a], so that global views of near surface CDOM have become available. With regard to the ocean interior, the situation is by far less favorable. Apart from coastal zones, influenced by rivers and land drainage, where the rather high CDOM concentrations have been documented, CDOM absorption in the open ocean is generally extremely low and less documented. Actually, it cannot be accurately measured within the visible part of the spectrum by using conventional spectroscopic instrumentation with $10 \mathrm{~cm}$ quartz-windowed cells. Only fluorometric determinations (with UV excitation) or (emission/excitation) spectrofluorometry are sensitive enough to be significant in open ocean [e.g., Yamashita and Tanoue, 2009; Omori et al., 2011]. The introduction of liquid capillary waveguide [Miller et al., 2002] and long optical path length $(\sim 2 \mathrm{~m})$ allows now CDOM absorption to be measured even in oligotrophic environment [Nelson et al., 2007; Swan et al., 2009; Bricaud et al., 2010]. Such determinations require extremely clean procedures (preparation of pure water reference deprived from any organic substance, adjustment of the refractive index between the sample and the reference). For these reasons, only few determinations with this new technique have been presently performed in open ocean waters, and $\mathrm{a}_{\mathrm{y}}$ is one of the least documented bio-optical properties within the databases. The deployment of Bio-Argo floats and the method here presented have the potential to fill the gap in this domain by increasing the geographical density and vertical resolution of CDOM observations.

[49] In spite of obvious limitations of the presently available CDOM fluorometric sensors in terms of sensitivity, it was possible to convert the fluorometric profiles into CDOM absorption profiles. The limited sensitivity of these sensors, however, is still the main weakness of the method, especially when realizing that in most of the oceanic waters the CDOM content is very low (e.g., Figure 2). A (desirable) improved sensitivity would allow linear regressions, such as those in Figures $5 \mathrm{a}-5 \mathrm{~d}$, to become more efficient when used as calibration tools.

[50] The conversion from ppb to $\mathrm{a}_{\mathrm{y}}$ is made thanks to an "indirect" spectrophotometry; indeed, it is not based on a direct determination of the CDOM absorption coefficient, but on the knowledge of the attenuation coefficients $\mathrm{K}_{\mathrm{d}}(412)$, combined with a simultaneous [Chla] determination. As a consequence, $\mathrm{a}_{\mathrm{y}}$ and $[\mathrm{Chl} a]$ retrievals heavily rest on the quality of the radiometric determinations. Nevertheless, it is worth remarking that absolute calibrations of these radiometers are not involved, since the derivation of $\mathrm{K}_{\mathrm{d}}$ coefficients are based on ratios of irradiance.

[51] The previous study focused on [Chla] retrieval [Xing et al., 2011] and the present one were both undertaken with the aim of developing data processing and quality control procedures for an assessment of key bio-optical parameters, to be systematically collected in a totally autonomous way and without possibility of checking the sensors responses over their lifetime. If a general consensus can be reached regarding these procedures (or others similar), an internal consistency in future databases built with the bio-optical parameters could be obtained, as it has been achieved for the physical parameters within the Argo program. Anyway, reprocessing and reversibility are always possible and facilitated when the data set has been homogeneously produced. Internal consistency is also an essential proviso when trying to validate bio-optical and biogeochemical models and extract trends in long-term records.

\section{Appendix A}

[52] An approximate estimate is sufficient for the particle backscattering, that is rather small compared with absorption. By adopting the old empirical relationship proposed by Gordon and Morel [1983] [see also Huot et al., 2008]

$$
\mathrm{b}_{\mathrm{p}}(550)=0.3[\mathrm{Chl} a]^{0.62}
$$


Assuming a $\lambda^{-1}$ spectral dependency for particle scattering and that the backscattering probability for "soft" particles is about or below 1\% [Twardowski et al., 2007], it comes $\mathrm{b}_{\mathrm{bp}}(412) \sim 0.004[\mathrm{Chl} a]^{0.62}$. When compared to equation $(5 \mathrm{~b})$, it appears that the ratio of backscattering to absorption is at the most of the order of $10 \%$.

[53] Acknowledgments. This paper represents a contribution to the Remotely Sensed Biogeochemical Cycles in the Ocean (remOcean) project, funded by the European Research Council (grant agreement 246777); to the Plateformes Autonomes et Biogéochimie Océanique (PABO) project, funded by Agence Nationale de la Recherche; to the Plateformes Autonomes Biogéochimiques: Instrumentation et Mesures (PABIM) project, funded by the Groupe Mission Mercator Coriolis; to the Biogeochemistry and Optics South Pacific Experiment (BIOSOPE) project of the Cycles Biogéochimiques Ecosystèmes et Ressouces (CYBER) program; and to the 111 project (B07036). We also would like to thank the NASA Ocean Biology Processing Group for processing and efficient distribution of the MODIS-A data. We are particularly grateful to John Cullen for useful comments and suggestions he made on earlier versions of the present paper.

\section{References}

Bricaud, A., A. Morel, M. Babin, K. Allali, and H. Claustre (1998), Variations of light absorption by suspended particles with the chlorophyll a concentration in oceanic (case 1) waters: Analysis and implications for bio-optical models, J. Geophys. Res., 103, 31,033-31,044, doi:10.1029/ 98JC02712.

Bricaud, A., M. Babin, H. Claustre, J. Ras, and F. Tieche (2010), Light absorption properties and absorption budget of Southeast Pacific waters, J. Geophys. Res., 115, C08009, doi:10.1029/2009JC005517.

Brown, C. A., Y. Huot, P. J. Werdell, B. Gentili, and H. Claustre (2008), The origin and global distribution of second order variability in satellite ocean color and its potential applications to algorithm development, Remote Sens. Environ., 112, 4186-4203, doi:10.1016/j.rse.2008.06.008.

Chen, R. F., and J. L. Bada (1992), The fluorescence of dissolved organic matter in seawater, Mar. Chem., 37, 191-221, doi:10.1016/ 0304-4203(92)90078-O.

Claustre, H., A. Sciandra, and D. Vaulot (2008), Introduction to the special section: Bio-optical and biogeochemical conditions in the Southeast Pacific in late 2004-The BIOSOPE program, Biogeosciences, 5, 679-691, doi:10.5194/bg-5-679-2008.

Claustre, H., et al. (2010), Bio-optical profiling floats as new observational tools for biogeochemical and ecosystem studies, in Proceedings of the OceanObs'09: Sustained Ocean Observations and Information for Society Conference, Venice, Italy, 21-25 September 2009, ESA Publ. WPP-306 [CD-ROM], edited by J. Hall et al., Eur. Space Agency, doi:105270/ OceanObs09.cwp.17.

Coble, P. G. (2007), Marine optical biogeochemistry: The chemistry of ocean color, Chem. Rev., 107, 402-418, doi:10.1021/cr050350+.

Cullen, J. J. (1982), The deep chlorophyll maximum: Comparing vertical profiles of chlorophyll a, Can. J. Fish. Aquat. Sci., 39, 791-803, doi:10.1139/f82-108.

Fichot, C. G., S. Sathyendranath, and W. L. Miller (2008), SeaUV and SeaUVc: Algorithms for the retrieval of UV/visible diffuse attenuation coefficients from ocean color, Remote Sens. Environ., 112, 1584-1602.

Garver, S. A., and D. A. Siegel (1997), Inherent optical property inversion of ocean color spectra and its biogeochemical interpretation: 1. Time series from the Sargasso Sea, J. Geophys. Res., 102, 18,607-18,625, doi:10.1029/96JC03243.

Gordon, H. R. (1989), Can the Lambert-Beer law be applied to the diffuse attenuation coefficient of ocean water?, Limnol. Oceanogr., 34, 1389-1409, doi:10.4319/1o.1989.34.8.1389.

Gordon, H. R., and A. Morel (1983), Remote Assessment of Ocean Color for Interpretation of Satellite Visible Imagery: A Review, 114 pp., Springer, New York.

Hansell, D. A. (2002), DOC in the global ocean carbon cycle, in Biogeochemistry of Marine Dissolved Organic Matter, edited by D. A. Hansell and C. A. Carlson, chap. 15, pp. 685-715, Academic, London.

Huot, Y., A. Morel, M. S. Twardowski, D. Stramski, and R. A. Reynolds (2008), Particle optical backscattering along a chlorophyll gradient in the upper layer of the eastern South Pacific Ocean, Biogeosciences, 5, 495-507, doi:10.5194/bg-5-495-2008.

International Ocean-Color Coordinating Group (IOCCG) (2011), BioOptical Sensors on Argo Floats, vol. 11, Reports of the International Ocean-Color Coordinating Group, edited by H. Claustre, Dartmouth, N. S., Canada.

Jerlov, N. G. (1968), Optical Oceanography, 194 pp., Elsevier, New York.
Johnson, K. S., W. M. Berelson, E. S. Boss, Z. Chase, H. Claustre, S. R. Emerson, N. Gruber, A. Körtzinger, M. J. Perry, and S. C. Riser (2009), Observing biogeochemical cycles at global scales with profiling floats and gliders: Prospects for a global array, Oceanography, 22 , 216-225, doi:10.5670/oceanog.2009.81.

Jørgensen, L., C. A. Stedmon, T. Kragh, S. Markager, M. Middelboe, and M. Søndergaard (2011), Global trends in the fluorescence characteristics and distribution of marine dissolved organic matter, Mar. Chem., 126, 139-148, doi:10.1016/j.marchem.2011.05.002.

Kalle, K. (1938), Zum Problem der Meereswasserfarbe, Ann. Hydrogr. Mar. Meteorol., 66, 1-13.

Kalle, K. (1949), Fluoreszenz und Gelbstoff im Bottnischen und Finnischen Meerbusen, Ocean Dyn., 2, 117-124, doi:10.1007/BF02225972.

Kalle, K. (1966), The problem of gelbstoff in the sea, Oceanogr. Mar. Biol., 4, 91-104.

Kramer, C. J. M. (1979), Degradation by sunlight of dissolved fluorescing substances in the upper layers of the eastern Atlantic Ocean, Neth. J. Sea Res., 13, 325-329, doi:10.1016/0077-7579(79)90009-7.

Lee, Z. P., and C. M. Hu (2006), Global distribution of Case-1 waters: An analysis from SeaWiFS measurements, Remote Sens. Environ., 101, 270-276, doi:10.1016/j.rse.2005.11.008.

Maritorena, S., D. A. Siegel, and A. R. Peterson (2002), Optimization of a semianalytical ocean color model for global-scale applications, Appl. Opt., 41, 2705-2714, doi:10.1364/AO.41.002705.

Miller, R. L., M. Belz, C. Del Castillo, and R. Trzaska (2002), Determining CDOM absorption spectra in diverse coastal environments using a multiple pathlength, liquid core waveguide system, Cont. Shelf Res., 22, 1301-1310, doi:10.1016/S0278-4343(02)00009-2.

Morel, A. (1974), Optical properties of pure water and pure sea water, in Optical Aspects of Oceanography, edited by N. G. Jerlov and E. S. Nielsen, pp. 1-24, Academic, San Diego, Calif.

Morel, A., and B. Gentili (2004), Radiation transport within oceanic (case 1) water, J. Geophys. Res., 109, C06008, doi:10.1029/2003JC002259.

Morel, A., and B. Gentili (2009a), A simple band ratio technique to quantify the colored dissolved and detrital organic material from ocean color remotely sensed data, Remote Sens. Environ., 113, 998-1011, doi:10.1016/j.rse.2009.01.008.

Morel, A., and B. Gentili (2009b), The dissolved yellow substance and the shades of blue in the Mediterranean Sea, Biogeosciences, 6, 2625-2636, doi:10.5194/bg-6-2625-2009.

Morel, A., B. Gentili, H. Claustre, M. Babin, A. Bricaud, J. Ras, and F. Tieche (2007a), Optical properties of the "clearest" natural waters, Limnol. Oceanogr., 52, 217-229, doi:10.4319/lo.2007.52.1.0217.

Morel, A., Y. Huot, B. Gentili, P. J. Werdell, S. B. Hooker, and B. A. Franz (2007b), Examining the consistency of products derived from various ocean color sensors in open ocean (case 1) waters in the perspective of a multi-sensor approach, Remote Sens. Environ., 111, 69-88, doi:10.1016/ j.rse.2007.03.012.

Morel, A., H. Claustre, and B. Gentili (2010), The most oligotrophic subtropical zones of the global ocean: Similarities and differences in terms of chlorophyll and yellow substance, Biogeosciences, 7, 3139-3151, doi:10.5194/bg-7-3139-2010.

Nelson, N. B., D. A. Siegel, and A. F. Michaels (1998), Seasonal dynamics of colored dissolved material in the Sargasso Sea, Deep Sea Res., Part I, 45, 931-957, doi:10.1016/S0967-0637(97)00106-4.

Nelson, N. B., D. A. Siegel, C. A. Carlson, C. Swan, W. M. Smethie Jr., and S. Khatiwala (2007), Hydrography of chromophoric dissolved organic matter in the North Atlantic, Deep Sea Res., Part I, 54, 710-731, doi:10.1016/j.dsr.2007.02.006.

Omori, Y., T. Hama, M. Ishii, and S. Saito (2011), Vertical change in the composition of marine humic-like fluorescent dissolved organic matter in the subtropical western North Pacific and its relation to photoreactivity, Mar. Chem., 124, 38-47, doi:10.1016/j.marchem.2010.11.005.

O'Reilly, J. E., et al. (2000), Ocean color chlorophyll a algorithms for SeaWiFS, OC2, and OC4: Version 4, in SeaWiFS Postlaunch Calibration and Validation Analyses: Part 3, pp. 9-23, NASA, Greenbelt, Md.

Pope, R. M., and E. S. Fry (1997), Absorption spectrum (380-700 nm) of pure water. II. Integrating cavity measurements, Appl. Opt., 36, 8710-8723, doi:10.1364/AO.36.008710.

Proctor, C. W., and C. S. Roesler (2010), New insights on obtaining phytoplankton concentration and composition from in situ multispectral chlorophyll fluorescence, Limnol. Oceanogr. Methods, 8, 695-708, doi:10.4319/lom.2010.8.695.

Ras, J., H. Claustre, and J. Uitz (2008), Spatial variability of phytoplankton pigment distributions in the subtropical South Pacific Ocean: Comparison between in situ and predicted data, Biogeosciences, 5, 353-369, doi:10.5194/bg-5-353-2008.

Roemmich, D., G. Johnson, S. Riser, R. Davis, J. Gilson, W. B. Owens, and S. Garzoli (2009), The Argo program: Observing the global ocean 
with profiling floats, Oceanography, 22, 34-43, doi:10.5670/oceanog. 2009.36

Siegel, D. A., S. Maritorena, N. B. Nelson, D. A. Hansell, and M. LorenziKayser (2002), Global distribution and dynamics of colored dissolved and detrital organic materials, J. Geophys. Res., 107(C12), 3228 , doi:10.1029/2001JC000965.

Siegel, D. A., S. Maritorena, N. B. Nelson, and M. J. Behrenfeld (2005) Independence and Interdependencies among global ocean color properties: Reassessing the bio-optical assumption, J. Geophys. Res., 110, C07011, doi:10.1029/2004JC002527.

Swan, C. M., D. A. Siegel, N. B. Nelson, C. A. Carlson, and E. Nasir (2009), Biogeochemical and hydrographic controls on chromophoric dissolved organic matter distribution in the Pacific Ocean, Deep Sea Res., Part I, 56, 2175-2192, doi:10.1016/j.dsr.2009.09.002.

Twardowski, M. S., H. Claustre, S. A. Freeman, D. Stramski, and Y. Huot (2007), Optical backscattering properties of the "clearest" natural waters, Biogeosciences, 4, 1041-1058, doi:10.5194/bg-4-1041-2007.

Vodacek, A., N. V. Blough, M. D. DeGrandpre, E. T. Peltzer, and R. K. Nelson (1997), Seasonal variation of CDOM and DOC in the
Middle Atlantic Bight: Terrestrial inputs and photooxidation, Limnol. Oceanogr., 42, 674-686, doi:10.4319/lo.1997.42.4.0674.

Xing, X., A. Morel, H. Claustre, D. Antoine, F. D’Ortenzio, A. Poteau, and A. Mignot (2011), Combined processing and mutual interpretation of radiometry and fluorimetry from autonomous profiling bio-Argo floats: Chlorophyll a retrieval, J. Geophys. Res., 116, C06020, doi:10.1029/ 2010JC006899.

Yamashita, Y., and E. Tanoue (2009), Basin scale distribution of chromophoric dissolved organic matter in the Pacific Ocean, Limnol. Oceanogr. 54, 598-609, doi:10.4319/1o.2009.54.2.0598.

H. Claustre, F. D’Ortenzio, A. Morel, and A. Poteau, Laboratoire d'Océanographie de Villefranche, Unité Mixte de Recherche 7093, Centre National de la Recherche Scientifique, F-06238 Villefranche-sur-Mer, France.

X. Xing, College of Physical and Environmental Oceanography, Ocean University of China, Qingdao, China. 